This item was submitted to Loughborough's Research Repository by the author.

Items in Figshare are protected by copyright, with all rights reserved, unless otherwise indicated.

\title{
Feasibility and biocompatibility of 3D-printed photopolymerized and laser sintered polymers for neuronal, myogenic, and hepatic cell types
}

\section{PLEASE CITE THE PUBLISHED VERSION}

https://doi.org/10.1002/mabi.201800113

\section{PUBLISHER}

(c) Wiley

\section{VERSION}

AM (Accepted Manuscript)

\section{PUBLISHER STATEMENT}

This work is made available according to the conditions of the Creative Commons Attribution-NonCommercialNoDerivatives 4.0 International (CC BY-NC-ND 4.0) licence. Full details of this licence are available at: https://creativecommons.org/licenses/by-nc-nd/4.0/

\section{LICENCE}

CC BY-NC-ND 4.0

\section{REPOSITORY RECORD}

Rimington, Rowan, Andrew Capel, Darren J. Player, Richard Bibb, Steven Christie, and Mark Lewis. 2018. "Feasibility and Biocompatibility of 3d-printed Photopolymerized and Laser Sintered Polymers for Neuronal, Myogenic, and Hepatic Cell Types". Loughborough University. https://hdl.handle.net/2134/32940. 
Feasibility and Biocompatibility of 3D Printed Photo-Polymerised and Laser Sintered Polymers for Neuronal, Myogenic and Hepatic Cell Types

Rowan P. Rimington ${ }^{1}$, Andrew J. Capel ${ }^{1,2}$, Darren J. Player ${ }^{1,4}$, Richard J. Bibb ${ }^{3}$, Steven D. R. Christie $^{2}$, Mark P. Lewis ${ }^{1 *}$.

${ }^{1}$ Musculoskeletal Biology Research Group, School of Sport, Exercise and Health Sciences, Loughborough University, Loughborough, Leicestershire, LE11 3TU, UK

${ }^{2}$ Department of Chemistry, School of Science, Loughborough University, Loughborough, Leicestershire, LE11 3TU, UK

${ }^{3}$ Design School, Loughborough University, Leicestershire, Loughborough, LE11 3TU, UK.

${ }^{4}$ Institute of Orthopaedics and Musculoskeletal Science, Division of Surgery and Interventional Science, University College London, Stanmore, Middlesex, HA7 4LP.

\section{Corresponding Author:}

Professor Mark Lewis

Chair in Musculoskeletal Biology

Loughborough University

M.P.Lewis@lboro.ac.uk

01509226430 


\begin{abstract}
The integration of additive manufacturing (AM) technology within biological systems holds significant potential, specifically when refining the methods utilised for the creation of in vitro models. Therefore, examination of cellular interaction with the physical/physico-chemical properties of 3D printed polymers is critically important. In this work, skeletal muscle $\left(\mathrm{C}_{2} \mathrm{C}_{12}\right)$, neuronal (SH-SY5Y) and hepatic (HepG2) cell lines were utilised to ascertain critical evidence of cellular behaviour in response to 3D printed candidate polymers; Clear-FL (stereolithography, SL), PA-12 (laser sintering, LS) and VeroClear (PolyJet). This research outlines initial critical evidence for a framework of polymer/AM process selection when 3D printing biologically receptive scaffolds, derived from industry standard, commercially available AM instrumentation. $\mathrm{C}_{2} \mathrm{C}_{12}$, SH-SY5Y and HepG2 cells favoured LS polymer PA-12 for applications in which cellular adherence is necessitated. However, cell type specific responses were evident when cultured in the chemical leachate of photo-polymers (Clear-FL and VeroClear). With the increasing prevalence of 3D printed bio-interfaces, the development of rigorous cell type specific biocompatibility data is imperative. Supplementing the currently limited database of functional 3D printed biomaterials affords the opportunity for experiment-specific AM process and polymer selection, dependent on biological application and intricacy of design features required.
\end{abstract}

Key Words: 3D Printing; Skeletal Muscle; Neuronal; Hepatocyte; Biocompatibility. 


\section{Introduction}

The possibility of three-dimensional (3D) printing (also known as Additive Manufacturing) bespoke biologically receptive parts, has driven the increasing application of Additive Manufacture (AM) technologies in biological systems. Techniques such as Fused Deposition Modelling (FDM) ${ }^{[1]}$ photopolymerisation processes such as stereolithography $(\mathrm{SL})^{[2,3]}$ and PolyJet printing, in addition to powder-based particle consolidation laser sintering (LS) ${ }^{[4]}$ technology have all previously been utilised to provide devices/scaffolds for bioengineering. ${ }^{[5-11]}$ However, the numerous advantages of AM, including design freedom and rapid production without moulds or tooling, are currently offset by a lack of fully characterised biocompatible materials. ${ }^{[12,13]}$

FDM affords a variety of biocompatible polymers with the capability to control and influence cellular phenotype, ${ }^{[14]}$ however such compatibility is, in part, negated when geometries with design features of increasing complexity are required. Despite being the most widely used, inexpensive and readily available 3D printing process, the diverse application of AM across scientific disciplines has elicited a trend toward the commercialisation of alternative processes capable of manufacturing such advanced geometries. SL and jetting based printing afford the capability to produce sophisticated designs, however the chemical complexity of the photo-sensitive resins typically result in non-biocompatible parts. ${ }^{[15]}$ These devices typically require time-consuming polymer surface modification in order to facilitate cellular compatibility. ${ }^{[16]}$ Comparable design complexities are attainable when printing with LS, however the accessibility of such technology has previously been commercially limited. Despite recent developments in the commercialisation of 3D printing technology toward user-friendly desktop appliances, investigations detailing the biocompatibility of useable polymers remain scarce. As such, the development of a wide-ranging knowledge base of AM candidate polymers derived across a range of advanced 3D printing processes remains imperative. ${ }^{[17]}$

Favourable candidate polymers for biological integration often require commercially available and accessible resins of transparent/clear appearance, to enable the visualisation of cellular samples within engineered devices. Polymers such as SL desktop appliance FormLabs ${ }^{\mathrm{TM}}$ Clear-FLGPCL02 resin and PolyJet VeroClear-RGD810 resin, which can form optically transparent structures, satisfy the criteria. 
In addition, biologically amenable candidate Nylon-6 polymers $^{[18]}$ have previously been documented, outlining the applicability of LS polyamide-12 (PA-12) when fabricating biocompatible devices. ${ }^{[19]}$

3D printed biocompatible polymers hold significant importance for tissue and biochemical engineering applications, with the methods required to construct the models that examine highly complex cellular physiological processes currently being revolutionised by AM. ${ }^{[6,20-27]}$ Pertinent to this are tissue engineered in vitro models, ${ }^{[28-31]}$ designed to replicate the in vivo cellular and molecular mechanisms that regulate musculoskeletal ${ }^{[32]}$ and neuromuscular disorders. ${ }^{[33]}$ As such, defining the compatibility of mammalian cells frequently used within these models; $\mathrm{C}_{2} \mathrm{C}_{12}$ murine skeletal myoblasts $^{[34]}$ and SH-SY5Y neuroblastoma ${ }^{[35]}$ human derived cell lines are of particular relevance. This is primarily due to the lack of availability of primary tissue, and their capability to afford physiologically representative in vitro models of native human in vivo tissues. Human derived HepG2 hepatocellular carcinoma ${ }^{[36]}$ cell line also holds significant importance due to their use within pharmaceutical toxicity assessments. Cytochrome P450 enzymes are of specific interest within toxicology research, ${ }^{[37-39]}$ due to their central role in drug metabolism ${ }^{[40]}$, outlining the necessity for their inclusion within this research.

Due to the diverse range of printed devices within biological systems, it is of paramount importance to comprehend both the indirect and direct effects of 3D printable polymers. As such, this investigation sought to determine the direct (cells cultured directly on the polymer) and indirect (cells cultured in chemical leached medium) effect of three commercially available 3D printable polymers across three sophisticated AM processes. SL: Clear FLGPCL02 (FormLabs GmbH), PolyJet: VeroClear-RGD810 (Stratasys) and LS: PA2200 (which is a polyamide-12 PA-12, EOS GmbH) on $\mathrm{C}_{2} \mathrm{C}_{12}$, SH-SY5Y and HepG2 cellular compatibility. 


\section{Materials and Methods}

\subsection{D Printing and Sample Preparation}

3D printing was undertaken utilising the following processes and parameters: FormLabs Form $2^{\mathrm{TM}}$ machine using the clear resin FLGPCL02 set at $0.1 \mathrm{~mm}$ layer thickness. Stratasys Objet Connex $500^{\mathrm{TM}}$ using the VeroClear-RGD810 material (with SUP705 support material) set at $0.33 \mathrm{~mm}$ layer thickness and default speed/quality settings. EOS Formiga P100 ${ }^{\mathrm{TM}}$ using EOS PA2200 powder (PA12) at $0.1 \mathrm{~mm}$ layer thickness. 3D CAD modelling was performed using Siemens NX software (v8.5, Siemens) with completed .stl files verified using Materialise MiniMagics (Materialise NV). Completed .stl files were processed using manufacturer recommended software for each process.

Clear FLGPCL02 (Clear-FL) samples were removed from the build plate and cleaned in isopropanol to remove uncured resin, prior to being submersed and agitated in $70 \%$ industrial methylated spirit (IMS) for $\leq 30$ mins. VeroClear-RGD810 (VeroClear) and PA-12 samples were removed from build plates and cleaned using a soft abrasive brush to remove supports and un-sintered powder respectively. All samples were sterilised via UV for $\geq 1 \mathrm{~h}$, prior to being adhered to culture well plates using an inhouse bio-adhesive (aquarium glue) that has been found to be biocompatible. ${ }^{[14]}$ Once adhered, samples were rinsed with 70\% IMS and left for remaining liquid to evaporate, prior to being further treated with $1 \mathrm{x}$ phosphate buffered saline (PBS). Prior to experimental treatment, Clear-FL and VeroClear samples (preconditioned by the same processing steps as the final intended product) were exposed to 10 days incubation within static growth medium ( $5 \mathrm{ml}$, supplementary material Figure. S1) at $37^{\circ} \mathrm{C}$ to facilitate the withdrawal of potentially harmful chemical leachate from sample scaffolds. Each sample scaffold disc (30 mm Ø x $1 \mathrm{~mm}$ thick, surface area $\left.\sim 15 \mathrm{~cm}^{2}\right)$ provided a $3 \mathrm{~cm}^{2}$ per $\mathrm{ml}$ surface area to volume ratio and was designed to cover most of the culture area of a six-well plate. Where suitable, the methodology was devised with the international standards organisation (ISO 10993) guidelines taken into consideration (Table S1, supplementary material).

\subsection{Cell Culture}

$\mathrm{C}_{2} \mathrm{C}_{12}$ murine skeletal myoblasts, all below passage 9, were cultured in T80 flasks (Nunc ${ }^{\mathrm{TM}}$, Fisher Scientific, UK) in growth medium (GM); composed of 79 \% DMEM (Sigma), 20 \% FBS (Pan 
Biotech) \& $1 \%$ penicillin-streptomycin (Fisher) until $80 \%$ confluence was obtained. Incubated cells GM was changed every $24 \mathrm{~h}$ during the $72 \mathrm{~h}$ culture period, prior to transfer into differentiation medium (DM); 97 \% DMEM, 2 \% horse serum (Sigma) \& 1 \% penicillin-streptomycin for $120 \mathrm{~h}$. $\mathrm{C}_{2} \mathrm{C}_{12}$ cell DM was changed once after $72 \mathrm{~h}$, prior to remaining in culture for a further $48 \mathrm{~h}$. The SHSY5Y neuroblastoma cell line was cultured in T80 flasks in GM; 89 \% Glutamax (Sigma, UK) $10 \%$ FBS, $1 \%$ penicillin-streptomycin until $80 \%$ confluence was attained, prior to being harvested for experimental usage. SH-SY5Y cells were cultured for $48 \mathrm{~h}$ in GM prior to inducing neuronal differentiation via medium (DM) containing $10 \mu \mathrm{M}$ retinoic acid (Sigma, UK) differentiating agent for 72 h. HepG2 cells were cultured in T225 flasks (Nunc ${ }^{\mathrm{TM}}$, Fisher Scientific, UK) in GM; 88 \% Earls modified Eagles Medium (MEM, Sigma, UK), 10 \% FBS, 1 \% penicillin-streptomycin and $1 \%$ non-essential amino acids (NEAA, Sigma, UK) until $60 \%$ confluence was obtained, at which point cells were harvested for experimental treatments spanning $96 \mathrm{~h}$. HepG2 and SH-SY5Y mediums were changed every $24 \mathrm{~h}$ with all experimental cells below passage 6 . All cell lines were obtained from ECACC and incubated at $5 \% \mathrm{CO}_{2}$ atmosphere and $37^{\circ} \mathrm{C}$ (HERAcell 240i, Thermo Fisher, UK) for the duration of all experiments.

\subsection{Experimental Treatments}

Experiments were designed to simultaneously assess critical evidence of cellular viability, morphological observations and cell line specific phenotype characterisation, in response to the direct (cells cultured directly on the polymer) and indirect (cells cultured within chemical leachate) effects of each polymer. 3D printed samples were used to evaluate the direct $(n=2)$ and indirect $(n=2)$ biocompatibility of each polymer per repeat $(n=3)$. Experiments generated $n=6$ per condition, totalling $n=12$ per analyses at each specific time-point, derived from $n=3$ experimental repeats. This protocol was completed separately for each cell line $\left(\mathrm{C}_{2} \mathrm{C}_{12}\right.$, SH-SY5Y and HepG2).

To assess direct biocompatibility, $1 \times 10^{5}\left(\mathrm{C}_{2} \mathrm{C}_{12}\right.$, HepG2) or $1 \times 10^{4}$ (SH-SY5Y) cells were seeded either directly onto the 3D printed discs that had been adhered to wells and left for $\geq 1 \mathrm{~h}$ to allow for initial cellular adhesion, or to control (CON) wells. Once attached, 2 ml GM was added to each well. To assess the indirect biocompatibility of chemical leachate from each polymer, 3D printed discs were 
attached to the culture area of two wells that were acellular, containing only medium (MEDIA ONLY). Chemically leached medium was then transferred to its corresponding experimental well during each repeat, ensuring that cellular medium was directly representative of either cumulative polymer degradation or CON at each specific time-point. Each MEDIA ONLY well was preincubated with $2 \mathrm{ml} \mathrm{GM}$ for $24 \mathrm{~h}$ prior to commencing each experiment, to ensure cells were seeded within media that had been exposed to the chemical leachate of each polymer. Medium, once transferred to experimental wells, was replenished for further $24 \mathrm{~h}$ incubation prior to each subsequent media change. During the last $24 \mathrm{~h}$ in which the cells were cultured in GM, DM was added to the MEDIA ONLY wells in preparation to induce differentiation in $\mathrm{C}_{2} \mathrm{C}_{12}$ and SH-SY5Y cell cultures.

Cells were analysed for cell viability at cell line specific time-points and fixed for fluorescence imaging at DM120 h $\left(\mathrm{C}_{2} \mathrm{C}_{12}\right)$, DM72 h (SH-SY5Y) and GM96 h (HepG2) time-points. After concluding cellular viability analysis at experimental termination, cells were washed twice with $2 \mathrm{ml}$ PBS, prior to RNA isolation with cells being immersed and homogenised in $0.5 \mathrm{ml}$ TRIzol per well.

\subsection{Fluorescence Staining and Microscopy}

Cells were washed twice in $2 \mathrm{ml}$ PBS per well, fixed (3.7 \% Paraformaldehyde) and permeabilised (Triton X-100, Fisher, 1:500). $\mathrm{C}_{2} \mathrm{C}_{12}$ cells were stained using $f$-actin molecular probe rhodamine phalloidin (1:200; Life Technologies, Molecular Probes) for $\geq 1$ h. SH-SY5Y and HepG2 cells were blocked 5\% goat serum for 30 mins, labelled with monoclonal mouse anti- $\beta$-tubulin III (1:200; Sigma, UK) and Anti-Human Serum Albumin (ab10241) antibodies (1:100; Abcam, UK) respectively for $\geq 2$ h prior to being counterstained with AlexaFluor ${ }^{\circledR 488-c o n j u g a t e d ~ g o a t ~ a n t i ~ m o u s e ~ I g G ~(1: 200 ; ~ L i f e ~}$ technologies, Thermo Scientific) secondary fluorochrome for $\geq 1 \mathrm{~h}$. DAPI nuclear stain (1:2000; Life Technologies, Molecular Probes) was used to stain nuclei in all cell lines. Rhodamine phalloidin was excited at $540 \mathrm{~nm}$ and emitted at $565 \mathrm{~nm}$ and appears red in fluorescence images. Alexa Fluor ${ }^{\circledR} 488$ appears green and is indicative of tubulin (SH-SY5Y) or albumin (HepG2) expression at standardised exposures. DAPI was excited at $358 \mathrm{~nm}$ and emitted at $461 \mathrm{~nm}$ and appears blue.

Light micrographs were captured on a Leica DMIL LED Light Microscope. Fluorescence images 
were visualised using a Leica DM2500 fluorescence microscope (20x) with manufacturer's software (Leica Application Suite X). Images were analysed using IMAGE J 1.50a/Fiji (Java 1.6.0_24) software (National institute of Health, Bethesda, MD, USA). Image inclusion criteria were set at $\geq 5$ images per well. Myotube inclusion criteria were defined as containing $\geq 3$ nuclei per myotube. Cumulative frequencies were calculated to determine the number of measures required per myotube, in addition to the number of myotubes and neurites necessitated per image for each analysis. Analysis of nuclei number was performed using an in-house macro instruction designed for Fiji (Java 1.6.0_24) image analysis software (Image J 1.50a).

\subsection{Cell Viability alamarBlue ${ }^{\circledR}$ Assay}

Cellular viability reagent; alamarBlue ${ }^{\circledR}$ diluted 1:10 DMEM $\left(\mathrm{C}_{2} \mathrm{C}_{12}\right)$, Glutamax (SH-SY5Y) or MEM (HepG2) was used to assess cell viability and proliferation in $\mathrm{C}_{2} \mathrm{C}_{12}$ and SH-SY5Y at 72 and $120 \mathrm{~h}$ experimental time-points. HepG2 cells were analysed every $24 \mathrm{~h}$ across the $96 \mathrm{~h}$ culture period. Cells were washed twice with $2 \mathrm{ml}$ PBS prior to being treated with $2 \mathrm{ml}$ per well alamarBlue ${ }^{\circledR}$ stock solution and humidified $5 \% \mathrm{CO}_{2}$ at $37{ }^{\circ} \mathrm{C}$ for $4 \mathrm{~h} .100 \mu \mathrm{l}$ per well of solution was then added to a black well 96-well plate and analysed for fluorescence intensity. Increased fluorescence of alamarBlue ${ }^{\circledR}$ reagent is indicative of an increase in cellular viability. alamarBlue ${ }^{\circledR}$ fluorescence signal was excited at 540-570 $\mathrm{nm}$ (peak excitation: $570 \mathrm{~nm}$ ) and emitted at 580-610 nm (peak emission: $585 \mathrm{~nm})$.

\subsection{RNA extraction and Quantitative RT-PCR}

RNA was extracted using the TRIzol method, according to manufacturer's instructions (Sigma). RNA concentration and purity were obtained by UV spectroscopy at optical density (ODs) of 260 and 280 nm using a Nanodrop 2000 (Fisher, Rosklide, Denmark). All RNA samples were analysed in duplicate. Twenty nanograms of RNA were used per RT-PCR paired species-specific reaction for RPII- $\beta$ and MYH3 ( $\mathrm{C}_{2} \mathrm{C}_{12}$ ), two nanograms for RPII- $\beta$ and MAPT (SH-SY5Y) and two nanograms for RPII- $\beta$, CYP1A1, 1A2, 2D6 and 3A4 (HepG2, Table 1). All mRNA expression of cells cultured within direct/indirect polymer conditions is normalised to that of control, hence responses above or below control values are indicative of increased or decreased gene transcription. 
RT-PCR amplifications were carried out using Power SYBR Green RNA-to-C $\mathrm{C}_{\mathrm{T}} 1$ step kit (Qiagen) on a ViiA ${ }^{\mathrm{TM}}$ Real-Time PCR System (Applied bio-systems, Life Technologies), analysed using ViiA ${ }^{\mathrm{TM}}$ 7RUO Software. RT-PCR procedure was as follows: $50{ }^{\circ} \mathrm{C}, 10 \mathrm{~min}$ (for cDNA synthesis), $95^{\circ} \mathrm{C}, 5$ min (transcriptase inactivation), followed by $95{ }^{\circ} \mathrm{C}$, 10 sec (denaturation), $60{ }^{\circ} \mathrm{C}$, 30 sec (annealing/extension) for 40 cycles. Relative gene expression was calculated using the comparative $\mathrm{C}_{\mathrm{T}}\left(\Delta \Delta \mathrm{C}_{\mathrm{T}}\right)$ equation for normalised expression ratios; relative expression calculated as $2^{-\Delta \Delta C \mathrm{CT}}$, where $\mathrm{C}_{\mathrm{T}}$ is representative of the threshold cycle. ${ }^{[41]}$ RPII- $\beta$ was used as the housekeeping gene in all RTPCR assays. To compare conditions, one control sample from each experimental repeat $(n=3)$ per cell type was used as the calibrator condition in the $\mathrm{C}_{\mathrm{T}}\left(\Delta \Delta \mathrm{C}_{\mathrm{T}}\right)$ equation. RT-PCR data is presented as relative gene expression level, determined by the $\Delta \Delta \mathrm{C}_{\mathrm{T}}$ equation.

\section{Table 1}

Primers utilised for examination of $\mathrm{C}_{2} \mathrm{C}_{12}$, SH-SY5Y and HepG2 mRNA. (m) - Mouse, (h) - Human.

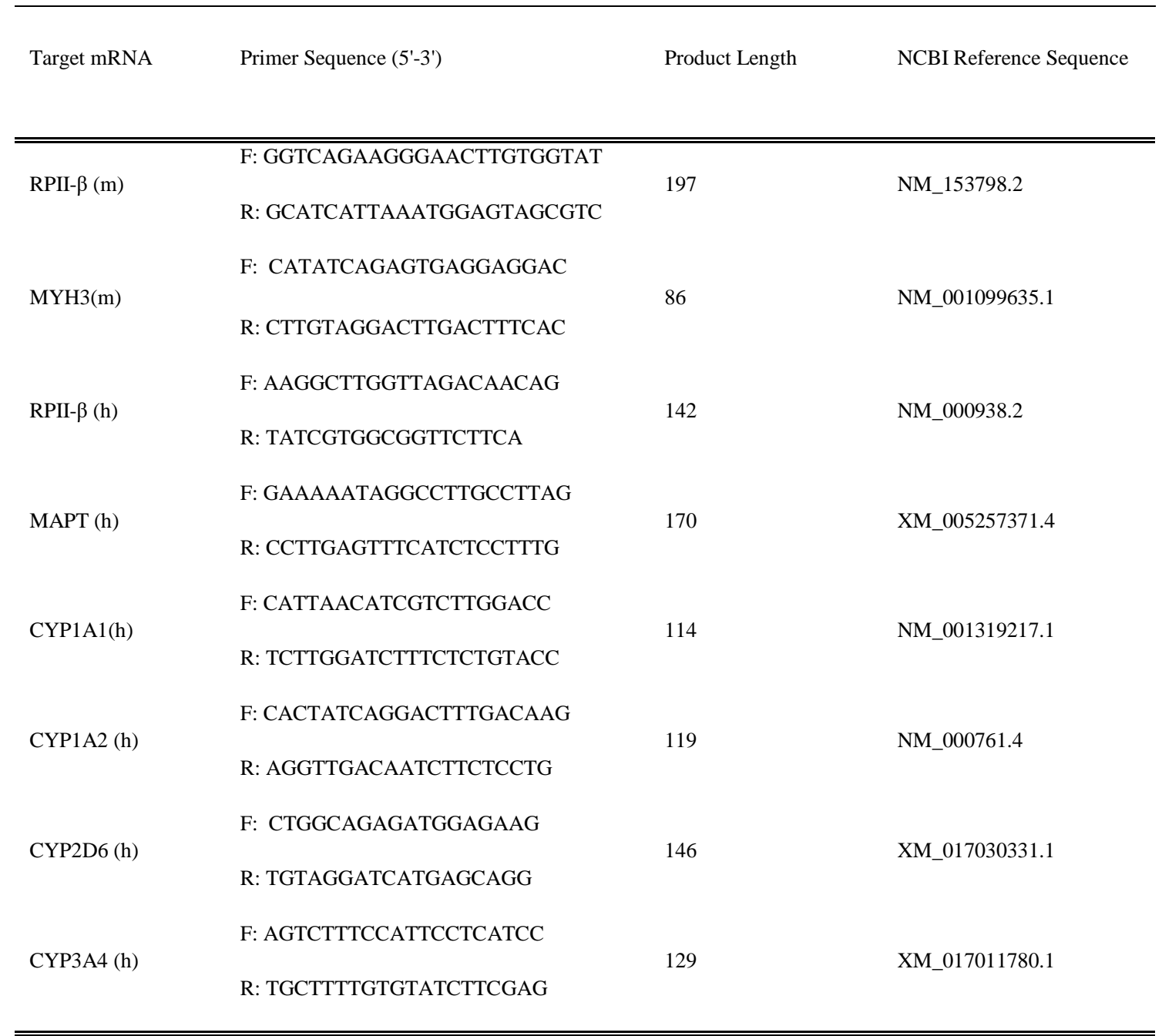




\subsection{Statistical analysis}

Statistical analyses and significance of data were determined using $\mathrm{IBM}^{\odot}$ SPSS $^{\odot}$ Statistics version 23. Mauchly's test of sphericity and Shapiro-Wilk tests were used to confirm homogeneity of variance and normal distribution of data respectively. Where parametric assumptions were met, a 4 x 2 (SHSY5Y \& $\mathrm{C}_{2} \mathrm{C}_{12}$ ) and 4 x 4 (HepG2) ANOVA was used for alamarBlue ${ }^{\circledR}$ analyses. One-way ANOVA (1 x 4) was used to analyse mRNA expression and morphological data; myotube number, myotube width, fusion index, nuclei number and neurite length only concerned with experimental termination time-points. Where significant interactions were observed, Bonferroni post-hoc analyses were used to analyse differences between conditions at specific time-points. Non-parametric Kruskal-Wallis $(H)$ analysis was undertaken where data violated parametric assumptions. Mann-Whitney $(U)$ tests were then utilised to determine significance between conditions, in accordance with Bonferroni correction to account for incremental type-1 error. All data is reported as mean \pm standard deviation (SD). Significance was assumed at $\mathrm{P} \leq 0.05$. 


\section{Results}

3.1. $\mathrm{C}_{2} \mathrm{C}_{12}$

\subsubsection{Cell Viability}

Cellular viability of $\mathrm{C}_{2} \mathrm{C}_{12}$ skeletal myoblasts cultured on 3D printed polymer scaffolds was significantly impaired across all conditions after GM72 h (Figure. 1 A, Clear-FL; P $=0.002$, VeroClear; $\mathrm{P}=0.002$, PA-12; $\mathrm{P}=0.002$ ) compared to control, outlining reduced rates of proliferation at this time-point. Despite reductions compared to control, cells cultured on VeroClear displayed significantly higher levels of metabolic activity compared to 3D printed Clear-FL ( $\mathrm{P}=0.002)$ and PA$12(\mathrm{P}=0.002)$ polymers, outlining preferential cell proliferative characteristics of this polymer scaffold compared to those derived from LS and SL processes. This response was in-part replicated after DM120 h time-points, with significantly diminished metabolic activity evident in Clear-FL (P = 0.002), VeroClear $(\mathrm{P}=0.009)$ and $\mathrm{PA}-12(\mathrm{P}=0.004)$ compared to control conditions. VeroClear displayed potentiated viability compared to Clear-FL ( $\mathrm{P}=0.002)$, however PA-12 cellular activity recovered to comparable levels. Significantly, reductions in viability documented in direct polymer conditions were completely ablated after GM72 and DM120 h in cells cultured in polymer chemical leachate, demonstrating comprehensive recovery of cellular viability within both proliferative and myogenic phases. Despite significantly potentiated metabolic activity observed in Clear-FL conditions when compared to VeroClear ( $\mathrm{P}=0.004)$ after DM120 h, it is reasonable to assert that cells cultured within chemical leachate maintained a viable phenotype across polymers, due to the homogeneity of metabolic activity observed when compared to control conditions.

a)

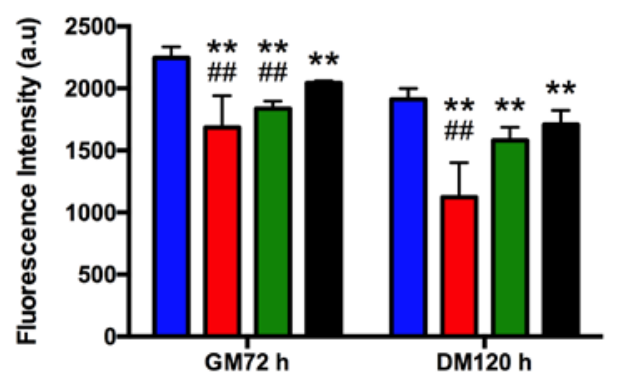

b)

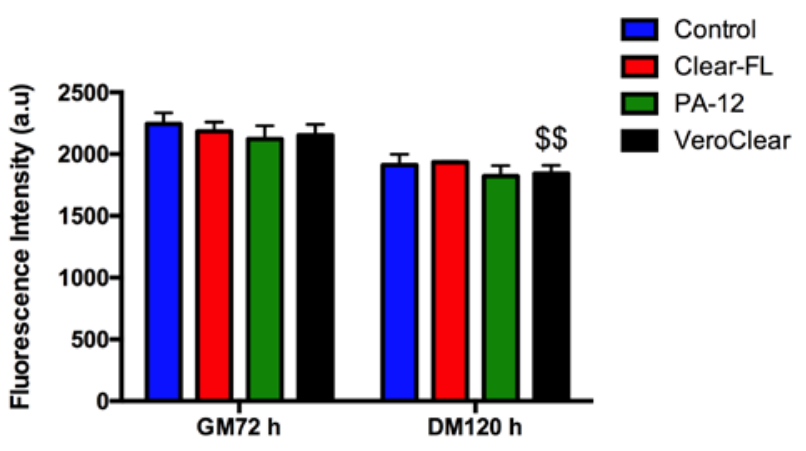


Figure.1. Cellular Viability of $\mathrm{C}_{2} \mathrm{C}_{12}$ cultured on (A) and within chemical leachate (B) of 3D printed polymers; ClearFLGPCL02 (Clear-FL), PA-12 and VeroClear-RGD810 (VeroClear) at GM72 and DM120 h time-points. Significantly different from * control, \$ Clear-FL and \# VeroClear. ** $\mathrm{P} \leq 0.01$.

\subsection{2. $C_{2} C_{12}$ Morphology}

$\mathrm{C}_{2} \mathrm{C}_{12}$ cells displayed significant morphological reductions in myotube number (Figure.2 B) when cultured directly on 3D printed Clear-FL $(\mathrm{P}=0.009)$ and VeroClear $(\mathrm{P}=0.010)$ polymer scaffolds. Non-significant reductions were observed in cells cultured on PA-12 scaffolds, outlining cellular preference for this polymer in comparison to photo-polymerisation centric polymer conditions, due to homogeneous myotube widths documented in Clear-FL, PA-12 and VeroClear conditions (Figure. 2 D). Fusion index analyses (Figure. 2 F) further supports this assertion, with reductions in fused nuclei evident in $\mathrm{C}_{2} \mathrm{C}_{12}$ cultured on VeroClear scaffolds compared to control $(\mathrm{P} \leq 0.0005)$ and $\mathrm{PA}-12(\mathrm{P}=$ 0.003). Reductions in myotube number (Figure. 2 C) were also documented in cells cultured in VeroClear chemical leachate compared to control $(\mathrm{P}=0.002)$. Despite homogeneous myotube widths being evident between all conditions (Figure. 2 E), fusion index analyses outlined inhibited nuclear fusion in VeroClear chemical leachate conditions when compared to control $(P=0.013)$, suggesting a potential inhibitory effect on the myogenic differentiation of $\mathrm{C}_{2} \mathrm{C}_{12}$ cells when interacting with the chemical parameters of this polymer (Figure. 2 G). 


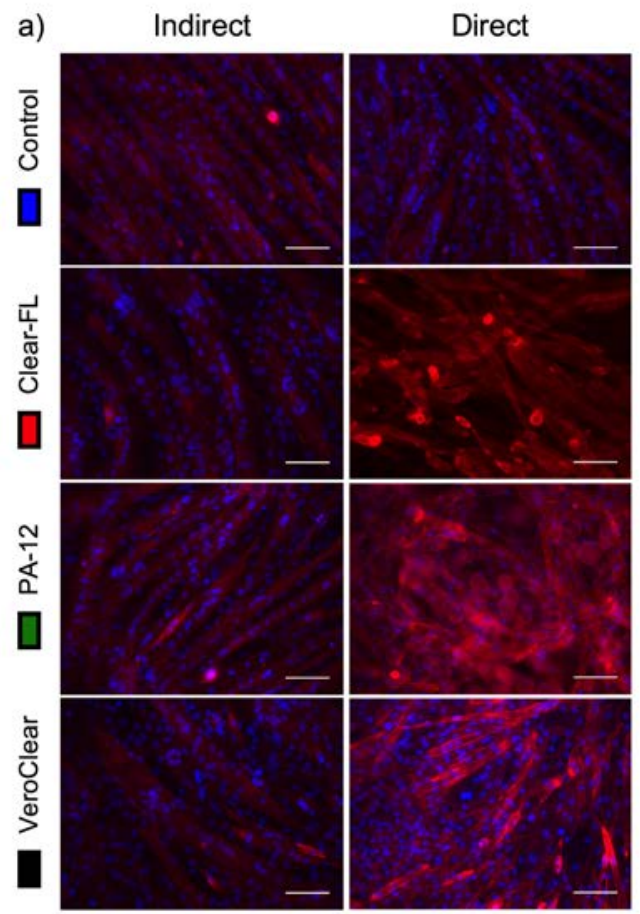

b)

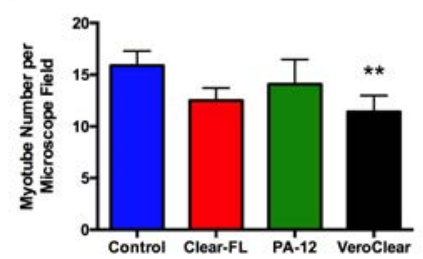

d)

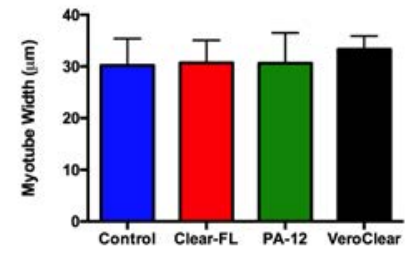

f)

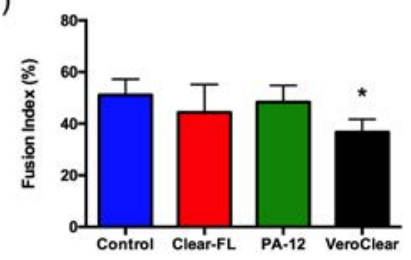

c)

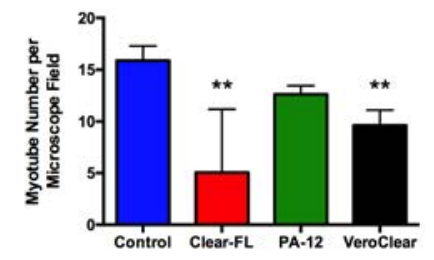

e)

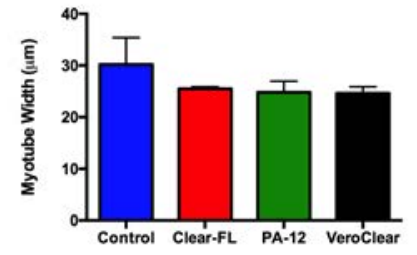

g)

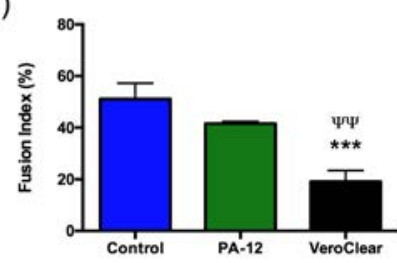

Figure.2. (a) Morphological staining of the actin cytoskeleton (red) and nucleic DNA (blue) of $\mathrm{C}_{2} \mathrm{C}_{12}$ cultured on (direct) and within chemical leachate (indirect) of 3D printed polymers; Clear-FLGPCL02 (Clear-FL), PA-12 and VeroClear-RGD810 (VeroClear) at DM120 h time-points. (b) Indirect and (c) direct myotube number. (d) Indirect and (e) direct myotube width. Fusion Index of $\mathrm{C}_{2} \mathrm{C}_{12}$ cultured in chemical leachate (f) and directly on (g) 3D printed polymers after DM120 h. Fusion index could not be determined for Clear-FL due to this polymer displaying high auto-fluorescence in response to multiple nuclear fluorochromes. Significantly different from * control and $\Psi$ PA-12. ** $\mathrm{P} \leq 0.01, * * * \mathrm{P} \leq 0.0005$. Scale bars $=100$ $\mu \mathrm{m}$.

\subsection{3. $C_{2} C_{12}$ MYH3 mRNA Expression}

Significant decreases in MYH3 (Figure.3), the embryonic heavy chain predominantly expressed within two dimensional skeletal muscle cultures, ${ }^{[42]}$ were documented in $\mathrm{C}_{2} \mathrm{C}_{12}$ cells cultured on $3 \mathrm{D}$ printed Clear-FL $(\mathrm{P}=0.010)$ and VeroClear $(\mathrm{P}=0.002)$ scaffolds. In addition, significant reductions were evident between VeroClear and PA-12 scaffolds $(\mathrm{P}=0.004)$, outlining the biocompatibility of this polymer. Reduced expression observed within Clear-FL and VeroClear direct conditions was inpart ameliorated from $7 \%$ to $60 \%$ and $49 \%$ of control MYH3 expression respectively when cultured within chemical leachate of these polymers, however these differences remained significant $(\mathrm{P}=$ 0.010, $\mathrm{P}=0.002)$. Although comparable MYH3 transcription was documented in direct PA-12 
scaffold cultures, this expression was significantly reduced compared to control in chemical leachate conditions $(\mathrm{P}=0.002)$.

A

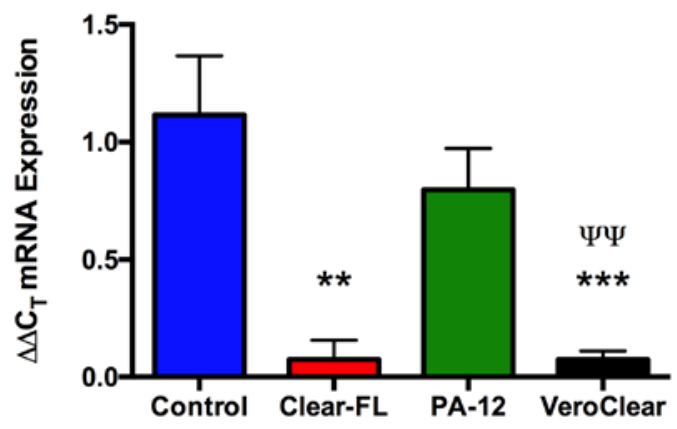

B

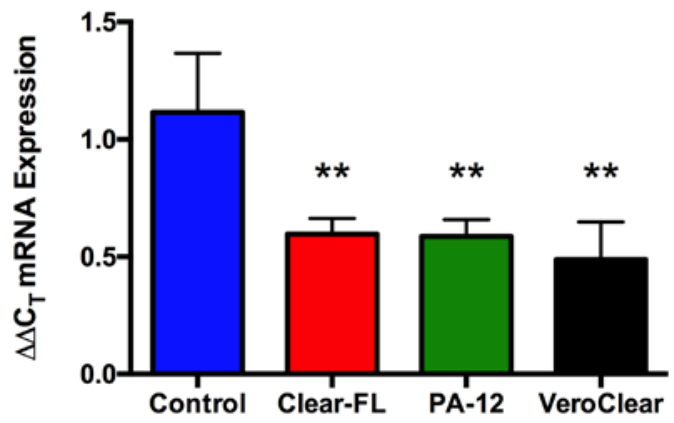

Figure.3. MYH3 expression of $\mathrm{C}_{2} \mathrm{C}_{12}$ cultured on (A) and within chemical leachate (B) of 3D printed polymers; ClearFLGPCL02 (Clear-FL), PA-12 and VeroClear-RGD810 (VeroClear) at DM120 h time-points. Significantly different from * control and $\Psi \mathrm{PA}-12 .{ }^{* *} \mathrm{P} \leq 0.01, * * * \mathrm{P} \leq 0.0005$. 


\subsection{SH-SY5Y}

\subsubsection{Cell Viability}

SH-SY5Y metabolic activity (Figure. 4 B and C) was significantly reduced when cells were cultured on Clear-FL ( $\mathrm{P}=0.002)$ and VeroClear $(\mathrm{P}=0.009)$ scaffolds compared to control, outlining inhibition of proliferation in response to physico-chemical and chemical characteristics of these polymers. This response remained consistent during the differentiation phase, with reduced viability observed in Clear FL $(\mathrm{P}=0.002)$ and VeroClear $(\mathrm{P}=0.002)$ compared to control. Continuous cellular replication was also evident within PA-12 conditions compared to Clear-FL $(\mathrm{P}=0.004)$, outlining viable proliferative cultures of SH-SY5Y cells on this polymer scaffold. Reduced viability in VeroClear scaffolds was ameliorated in chemical leachate conditions after GM48 h, however this response was not replicated in Clear-FL conditions, which remained significantly less metabolically active compared control $(\mathrm{P}=0.002)$, VeroClear $(\mathrm{P}=0.002)$ and $\mathrm{PA}-12(\mathrm{P}=0.002)$. Viable cultures were again evident in VeroClear and PA-12 chemical leachate conditions after DM72 h, however Clear-FL SH-SY5Y cell cultures remained significantly less viable than control $(\mathrm{P}=0.002)$ and PA-12 $(\mathrm{P}=$ $0.002)$.

\subsubsection{SH-SY5Y Morphology}

Significantly potentiated neurite axonal extension (Figure. 4 E) was observed in Clear-FL $(\mathrm{P}=0.002)$ and VeroClear $(\mathrm{P}=0.004)$ chemical leachate conditions when compared to control, with Clear-FL eliciting the longest neurites in culture compared to VeroClear $(\mathrm{P}=0.002)$ and PA-12 $(\mathrm{P}=0.002)$. Despite eliciting greater neurite lengths in culture, Clear-FL also displayed significantly reduced nuclei number (Figure. 4 D) compared to control $(P=0.015)$ and VeroClear $(P=0.002)$, corresponding with the reduced metabolic activity documented in this condition. Tubulin could not be presented in direct conditions due to high auto-fluorescence evident in response to the Alex-Fluor488 fluorochrome, with Clear-FL also highly auto-fluorescent in response to multiple nuclear fluorescent stains.

\subsubsection{SH-SY5Y MAPT mRNA Expression}

MAPT expression remained consistent across 3D printed polymer scaffolds in direct conditions 
(Figure. 4 F); however, transcription levels of this gene could not be determined for Clear-FL due to the low cell numbers that remained on the scaffold at DM72 h time-points. Potentiated expression of this gene was however evident in VeroClear conditions when compared to control $(\mathrm{P}=0.020)$ and Clear-FL ( $\mathrm{P}=0.039)$, outlining significantly enhanced axonal development in SH-SY5Y cells cultured within the chemical leachate of this polymer (Figure.4 G).

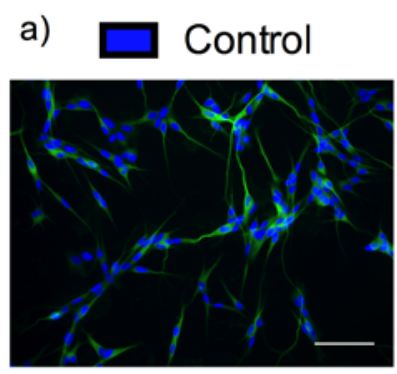

b)

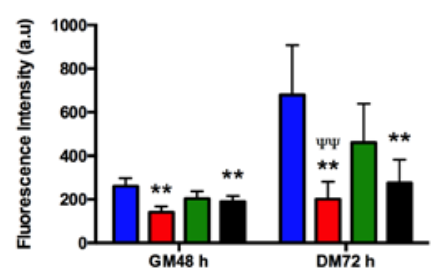

e)

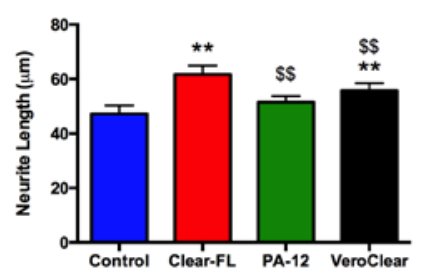

$\square$ Clear-FL

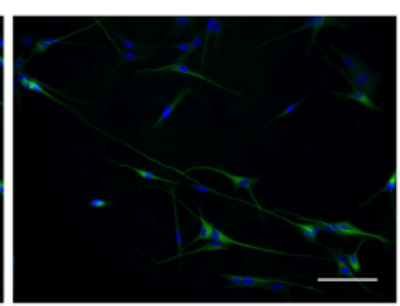

c)

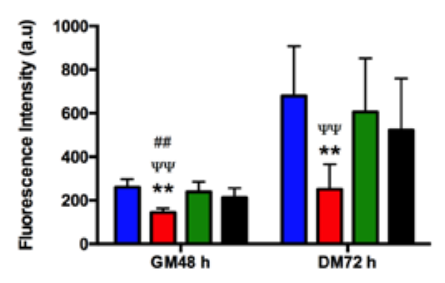

f)

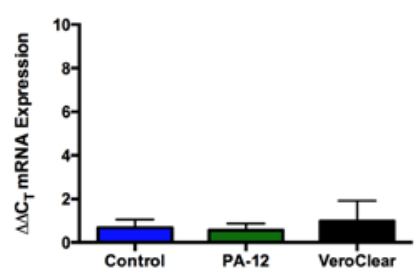

$\square$ VeroClear

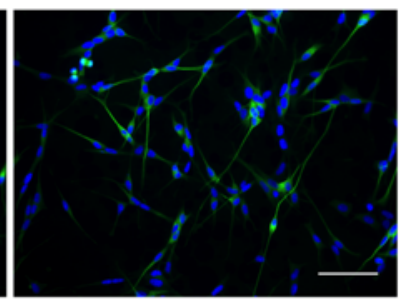

d)

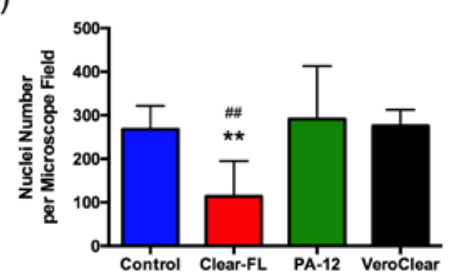

g)

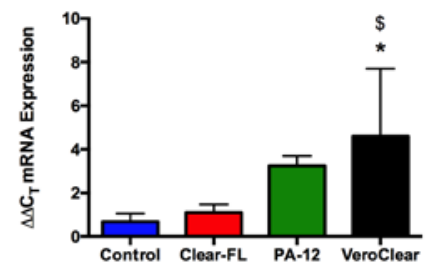

Figure.4. (a) Morphological staining for tubulin (green) and nucleic DNA (blue) of SH-SY5Y cells cultured in chemical leachate of 3D printed polymers; Clear-FLGPCL02 (Clear-FL), PA-12 and VeroClear-RGD810 (VeroClear). Cellular viability of SH-SY5Y cultured on (b) and within chemical leachate (c) of 3D printed polymers at GM48 and DM72 h timepoints. Nuclei number (d) and neurite length (e) of SH-SY5Y cultured in chemical leachate of 3D printed polymers. MAPT expression of SH-SY5Y cultured on (f) and within chemical leachate (g) of 3D printed polymers at DM120 h time-points. Significantly different from * control, $\Psi$ PA-12, \$ Clear-FL and \# VeroClear. * $\mathrm{P} \leq 0.05,{ }^{* *} \mathrm{P} \leq 0.01$. 


\subsection{HepG2}

\subsubsection{Cell Viability}

HepG2 cells displayed diminished viability (Figure. 5 A) after 24, 48, 72 and 96 h in culture on ClearFL and VeroClear scaffolds compared to control and PA-12 (P $\leq 0.0005)$, with reduced metabolic activity also evident in Clear-FL compared to VeroClear (24; $\mathrm{P} \leq 0.0005,48 ; \mathrm{P} \leq 0.0005,72 ; \mathrm{P}=$ 0.001, 96; $\mathrm{P}=0.007)$. Increasingly higher levels of viability were observed in PA-12 scaffolds, however this decrement remained significant compared to control conditions (24; $\mathrm{P}=0.008$, 48; $\mathrm{P}=$ $0.008,72 ; \mathrm{P}=0.001,96 ; \mathrm{P}=0.007)$. Diminished viability reported in direct conditions was rescued in chemical leachate PA-12 conditions, however remained significantly reduced at intermediate timepoints in VeroClear conditions (48; $\mathrm{P}=0.037,72 ; \mathrm{P}=0.023$ ) and consistently throughout Clear-FL leachate cell cultures $(24 ; \mathrm{P}=0.033,48 ; \mathrm{P} \leq 0.0005,72 ; \mathrm{P} \leq 0.0005,96 ; \mathrm{P}=0.003)$ despite biologically relevant phenotypic restoration (Figure. 5 B). In addition, PA-12 HepG2 cells displayed significantly potentiated metabolic activity compared to Clear-FL at $48(\mathrm{P}=0.003)$ and $72 \mathrm{~h}(\mathrm{P}=$ 0.014) time-points further outlining cellular preference for this polymer. 
a)

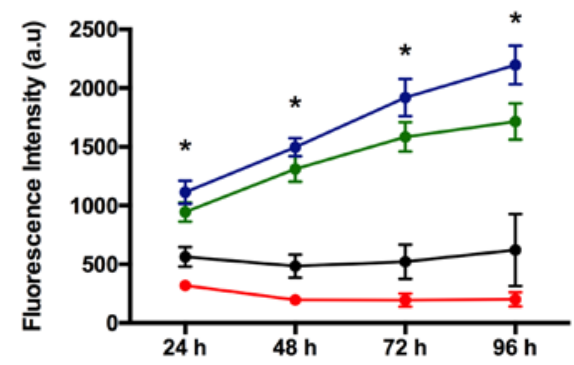

c)

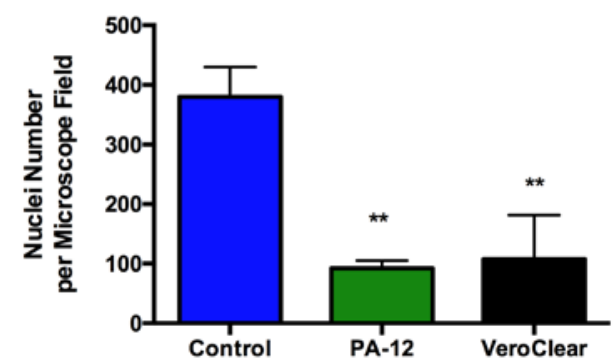

b)

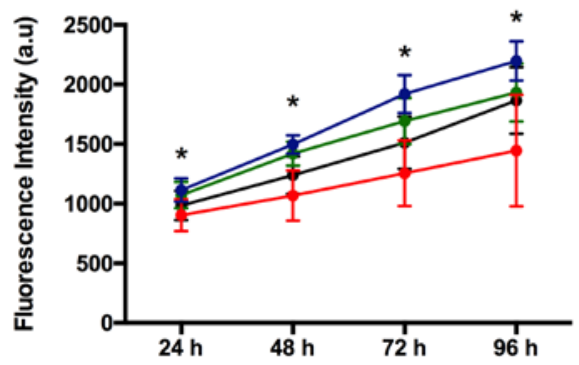

d)

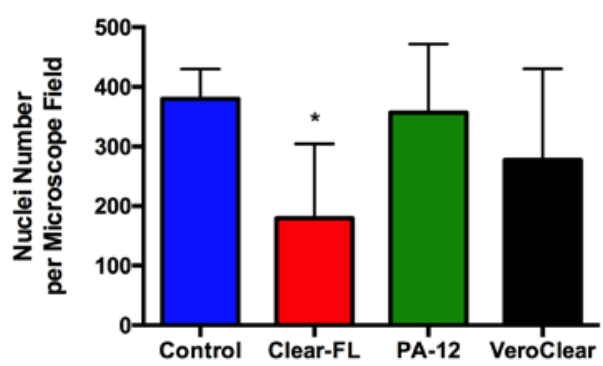

Figure.5. Metabolic activity of HepG2 cells cultured on (a) and within chemical leachate (b) of 3D printed polymer scaffolds; Clear-FLGPCL02 (Clear-FL), PA-12 and VeroClear-RGD810 (VeroClear). Nuclei number of HepG2 cells cultured on (c) and within chemical leachate (d) of 3D printed polymers. (a and $b$ * Significance within time-point $\mathrm{P} \leq 0.01$ ). Significantly different from * control. * $\mathrm{P} \leq 0.05, * * \mathrm{P} \leq 0.01$.

\subsubsection{HepG2 Morphology}

The metabolic activity of HepG2 cells cultured directly on polymer scaffolds demonstrated correlation with nuclear number (Figure. 5 C) evident after $96 \mathrm{~h}$ in culture, with significant decrements observed in VeroClear $(\mathrm{P}=0.002)$ conditions at this time-point. However, the reduced nuclei number in HepG2 cultured on PA-12 ( $\mathrm{P}=0.002)$ polymer scaffold appears to be a result of microscopic distortion; with cells co-existing amongst nylon particles at different ranges in the $\mathrm{Z}$ axis (Figure. 6 A), hence producing misrepresentative nuclear counts per image frame dependent on focal plane. Significant reductions were also documented in HepG2 nuclei when cultured in chemical leachate of Clear-FL $(\mathrm{P}=0.015)$ compared to control, outlining potential chemical inhibition of proliferation in response to this polymer (Figure. 5 D). 


\subsubsection{HepG2 Cytochrome P450 mRNA Expression}

HepG2 cytochrome P450 CYP1A1 mRNA expression was significantly up regulated in Clear-FL (P = 0.006) and VeroClear $(\mathrm{P}=0.017)$ direct polymer scaffold conditions (Figure.6 C), however potentiated HepG2 CYP1A2 and CYP2D6 transcription remained isolated to Clear-FL ( $\mathrm{P}=0.016)$, VeroClear conditions $(\mathrm{P}=0.001)$ respectively, outlining increases in the mechanisms associated with detoxification. Such increases in expression observed in direct polymer conditions, were completely ablated in the CYP1A1 and 2D6 enzymatic gene expression levels when cultured in chemical leachate of 3D printed polymers. However, despite apparent reductions in transcription levels, CYP1A2 remained significantly up regulated within Clear-FL $(\mathrm{P}=0.003)$ and VeroClear $(\mathrm{P} \leq 0.0005)$ polymer leachate (Figure. 6 D). 
a) $\square$ Control

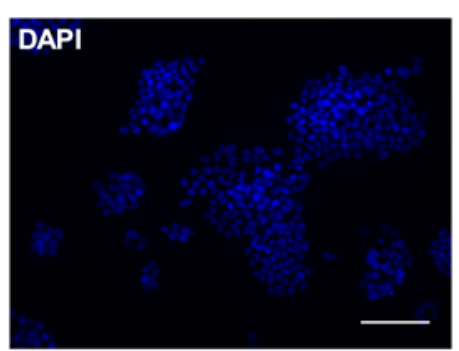

PA-12

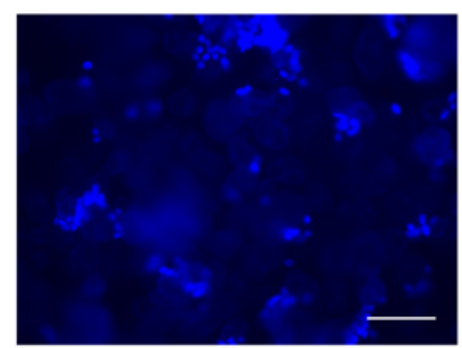

b) $\square$ Control
Clear-FL
VeroClear

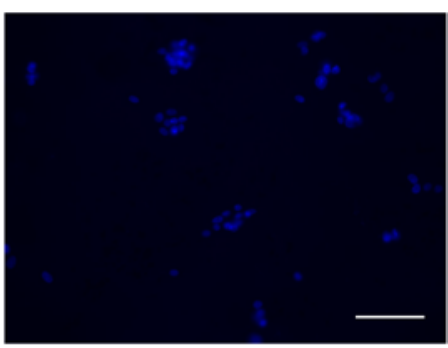

VeroClear

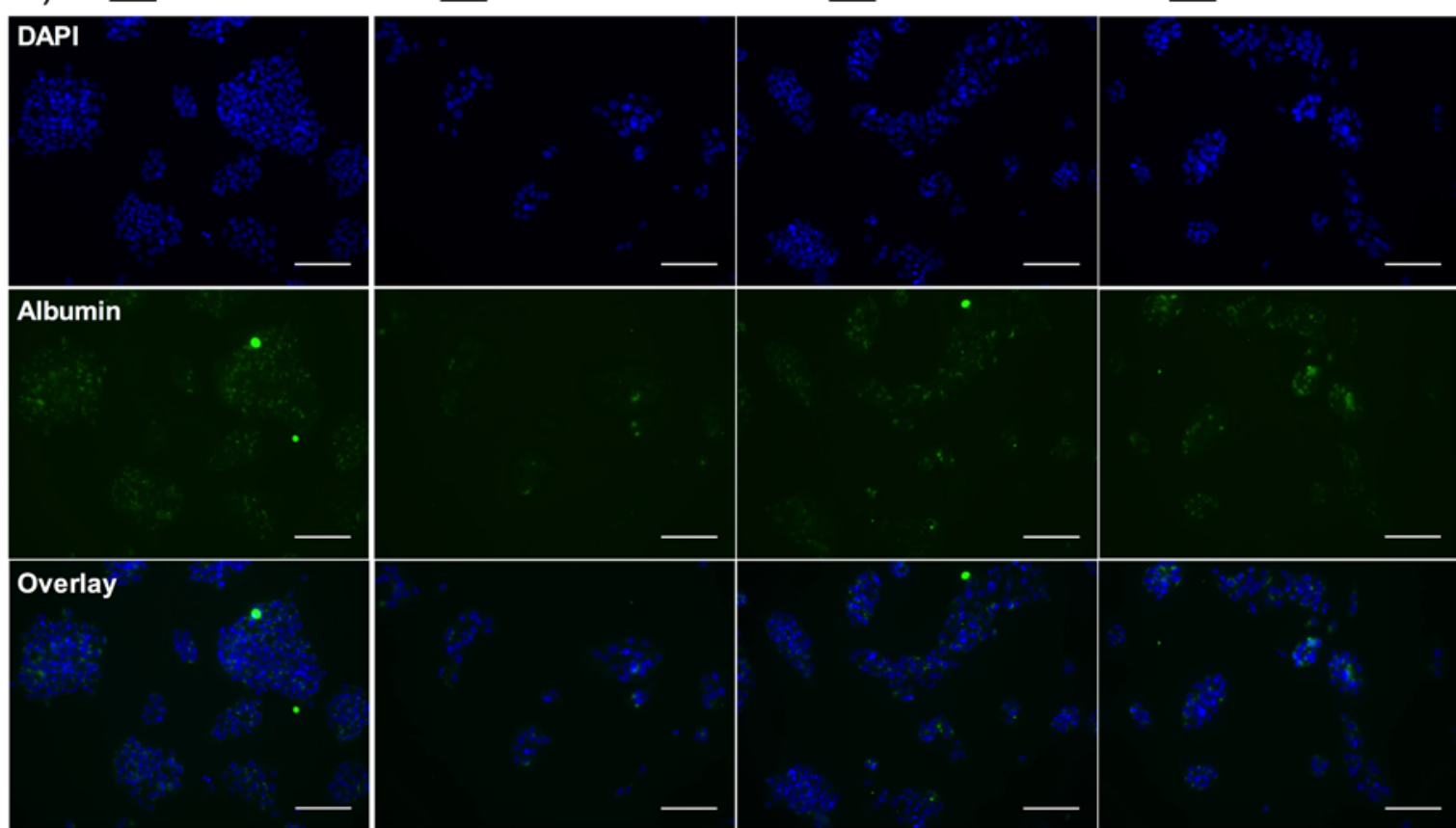

c)

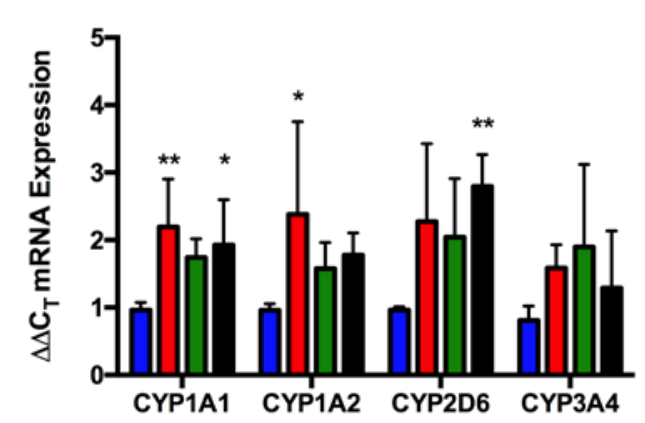

d)

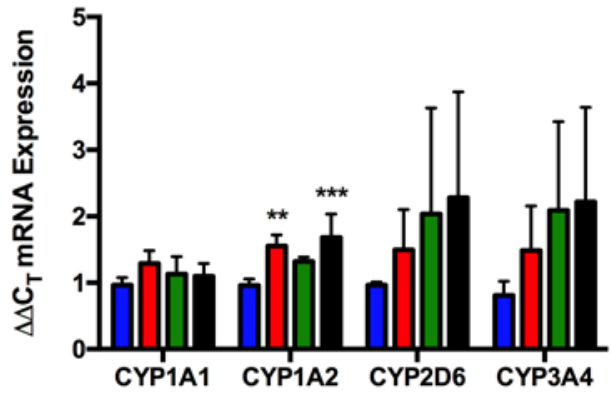

Figure.6. Morphological staining for albumin (green) and nucleic DNA (blue) of HepG2 cells cultured on (a) and within chemical leachate (b) of 3D printed polymer scaffolds; Clear-FLGPCL02 (Clear-FL), PA-12 and VeroClear-RGD810 (VeroClear). Albumin fluorescent staining could not be presented in direct conditions due to high auto-fluorescence evident in response to the Alex-Fluor488 fluorochrome, with Clear-FL also highly auto-fluorescent in response to multiple nuclear fluorochromes. Cytochrome P450 expression of HepG2 cultured on (c) and within chemical leachate (d) of 3D printed polymers at $96 \mathrm{~h}$ time-point. Significantly different from * control. $* \mathrm{P} \leq 0.05$, ** $\mathrm{P} \leq 0.01, * * * \mathrm{P} \leq 0.0005$. Scale bars $=$ $100 \mu \mathrm{m}$. 


\section{Discussion}

Understanding the cellular physiological interaction with the physical/physico-chemical properties of 3D printed polymers is of critical importance. Particularly when evaluating the specific AM process and polymer combination while creating physiologically representative in vitro models, ${ }^{[28-31]}$ that are utilised within tissue engineering and or pharmaceutical screening applications. This research demonstrates cell type specific biocompatibility across a range of industry standard 3D printing techniques; SL, LS and PolyJet, for incorporation within tissue engineering models of musculoskeletal ${ }^{[32]}$ and neurological disorders, ${ }^{[33]}$ in addition to pharmacological screening systems. ${ }^{[37]}$ In this work we used $\mathrm{C}_{2} \mathrm{C}_{12}$, SH-SY5Y and HepG2 cell lines in order to ascertain critical evidence of cellular behaviour in response to 3D printed candidate polymers due to their capacity to afford a range of optically transparent (Clear-FL and VeroClear) and bio-inert (PA-12) parts from commercially available and accessible AM instrumentation.

Whilst the chemical compositions of these polymers (specifically Clear-FL and VeroClear) are often commercially protected proprietary material formulations, it is possible to determine the general characteristics of these materials. UV curable photo-polymers are typically based on acrylates, epoxides and urethanes with the final material likely to be densely crosslinked. ${ }^{[43]}$ Specifically, the Clear-FL resin contains a proprietary mixture of methacrylate oligomers and monomers, as well as a photoinitiator. ${ }^{[44]}$ VeroClear resin contains acrylic monomer $(<30 \%)$, acrylic oligomer $(<15 \%)$, isobornyl acrylate $(<25 \%)$, photoinitiator $(<2 \%)$ and acrylic acid ester $(<0.3 \%) .{ }^{[45]}$ The composition of both the uncured liquid resins and chemically leached components for both Clear-FL and VeroClear were assessed via Nuclear Magnetic Resonance spectroscopy (NMR, Figure. S2 and S4 supplementary material) and Fourier Transform Infra-Red spectroscopic analysis (FTIR, Figure. S3 and S5 supplementary material). When analysing the uncured liquid Clear-FL resin via NMR, characteristic peaks were observed suggesting the presence of $\mathrm{C}=\mathrm{C}(5.5-6.25 \mathrm{ppm}), \mathrm{RCH}_{3}(4.35 \mathrm{ppm})$ as well as primary, secondary and tertiary aliphatic (1-2ppm) functionality within the materials. Each of these peaks remained present in the leached material, indicating uncured methacrylate oligomers and monomers constitutes the major leachate component. This hypothesis is further supported via FTIR analysis of Clear-FL resin and leachate, both indicating the presence of $-\mathrm{OH}(3370 \mathrm{~cm}-1$, 
stretch), C-H (2950cm-1, stretch), C=O (1700-1720 cm-1, stretch), as well as C=C (1637cm-1, stretch) identifying acrylate functionality within the sample. NMR analysis of uncured liquid VeroClear resin outlined presence of primary, secondary and tertiary aliphatic (0.7-1.2 ppm), $\mathrm{RCH}_{2}(1.25-2 \mathrm{ppm})$, $\mathrm{RCH}_{3}(3.7 \mathrm{ppm})$ and $\mathrm{C}=\mathrm{C}(5.5-6.5 \mathrm{ppm})$ indicating functionality typically associated with the presence of acrylic monomers, oligomers, isobornyl acrylates and acrylic acid esters. However, a reduction in methyl terminated esters was apparent whilst retaining characteristic acrylate functionality. This indicates a reduced presence of either the acrylic monomer or oligomer within the leachate samples. Further functional characterisation was achieved via FTIR, with characteristic peaks indicating the presence of $=\mathrm{C}-\mathrm{H}(2953 \mathrm{~cm}-1$, stretch $), \mathrm{C}=\mathrm{O}(1718 \mathrm{~cm}-1$, stretch $), \mathrm{C}=\mathrm{C}(1643 \mathrm{~cm}-1$, stretch) observed in both uncured resin and printed samples.

It is generally assumed that printed samples are densely crosslinked upon removal from their respective printers. Despite this, differences in the final solid state of printed parts may also be attributed to methods of resin curing. Whilst not typical, UV or thermal post-curing of PolyJet printed parts is employed to enhance the physical properties of finished parts for certain materials. The manufacturers of SL processes typically recommend employing UV post-curing of printed parts. This would indicate incomplete monomer crosslinking within the printed parts. SL uses dynamic mirrors to direct UV lasers towards a vat of uncured liquid resin. Whereas PolyJet deposits uncured resin layer by layer onto the build platform via multiple print heads, with the polymer being cured as it is deposited using UV lamps. Lasers utilised in SL are very specific in wavelength, highly accurate in position, but are often lower in power compared to UV lamps used within PolyJet printing processes. These lamps also have a wider spread of wavelengths emitted. In addition, in SL the scan strategy (pattern) described by the laser for each layer can be altered to improve accuracy and or speed. As such, the final solid state of SL printed parts will be dependent on a combination of the print settings (scan pattern, layer thickness, etc.), curing process, type of resin and specific machine. Data observed within NMR analyses indicated that compounds containing acrylate functionality (Clear-FL and VeroClear photo-polymers) appear to be the major component of leached compounds during the solvent extraction affecting the cell lines used. This indicates potentially incomplete crosslinking of 
monomer resin during the printing process. Adverse biological outputs upon the cell lines tested are likely a combination of not only the original chemical composition, but also the amount of such compounds being leached into the cellular medium. Cytotoxic effects of methacrylate monomers and oligomers have been previously reported in the literature. This is attributed to the induction of apoptosis, genotoxicity and cell cycle arrest. ${ }^{[46]}$ Further work has speculated that such toxicity may also be related to the generation of reactive oxygen species (ROS) within cell cultures. ${ }^{[47]}$ Structure toxicity relationships have also observed inverse correlation between cellular toxicity and compound lipophilicity, with the mechanism of these compounds likely membrane mediated. ${ }^{[48]}$ This response can however be reduced, and/or ameliorated through solvent extraction prior to cellular interaction as reported in this work.

It is possible that specific machine parameters and/or forms of UV or possibly thermal post-curing might improve the degree of complete crosslinking in 3D printed parts, which might in turn reduce the leaching of cytotoxic compounds. This is particularly the case in SL where there are more parameters that could be easily varied. For example, slower scan strategies with greater overlap of laser paths and thinner layers might ensure higher degrees of crosslinking during printing, with the compromise being much slower build speeds and potentially poorer dimensional accuracy. Certain special resins in PolyJet and SL already require thermal and or UV post-curing to achieve enhanced physical properties and these techniques could be explored to ensure a greater level of crosslinking. The improvements in physical properties, typically stiffness or toughness suggests that the post-curing does indeed lead to higher degrees of crosslinking. Future work should seek to investigate the effects of machine parameters and post-curing techniques on the leaching of toxic compounds.

Metabolic activity of $\mathrm{C}_{2} \mathrm{C}_{12}$ skeletal myoblasts cultured on VeroClear and PA-12 polymer scaffolds appeared to produce viable cultures within proliferation and differentiation phases, demonstrating evidence of initial cellular compatibility. Although cell cultures within scaffolds were significantly less metabolically active than in control conditions, this is often a consequence of the non-uniform polymer surfaces created by the AM processes. However, significant decrements in Clear-FL and VeroClear cellular viability observed coincided with reductions in myotube number, fusion index and 
MYH3 expression, outlining inhibition of myogenic differentiation and skeletal muscle maturation, despite comparable myotube widths. Such reductions were however not evident when cells were cultured on PA-12 scaffolds, with comparable morphological and transcriptional phenotypes evident. This further outlines the applicability of this polymer and favourability of LS when fabricating scaffolds for musculoskeletal tissue engineering applications. ${ }^{[28,29,33]}$

Reductions observed in cellular viability were however completely ameliorated in $\mathrm{C}_{2} \mathrm{C}_{12}$ cells exposed to chemical leachate of all 3D printed polymers at proliferative and differentiation time-points, outlining viable levels of metabolic activity in all conditions. Morphological parameters of skeletal muscle cellular phenotype remained consistent to that of control conditions in Clear-FL and PA-12 polymer leachate. However, reductions in myotube number and subsequent reductions in fusion efficiency evident in VeroClear conditions suggests an inhibitory effect of this polymer leachate on $\mathrm{C}_{2} \mathrm{C}_{12}$ myogenic differentiation, yet while retaining the proliferative capacity of this population. Transcriptional MYH3 regulation was statistically reduced compared to control, however substantial increases between direct and indirect Clear-FL and Vero-Clear conditions were apparent; further outlining the phenotypic recovery evident when exposed to chemical polymer leachate, as opposed to the physico-chemical characteristics of each polymer. Despite reduced MYH3 expression, morphological and metabolic indices outline viable cultures of in vitro skeletal muscle in both ClearFL and PA-12 conditions.

Viable cultures of neuronal SH-SY5Y cells were also evident when cultured on PA-12 polymer scaffolds at proliferative and differentiated time-points, however SH-SY5Y cells displayed diminished viability within Clear-FL and VeroClear conditions at GM48 and DM72 h time-points, outlining inhibition of cellular proliferation when cultured on 3D printed photo-polymer scaffolds. Despite the significant decrements in metabolic activity observed, MAPT transcriptional activation remained consistent across PA-12 and Vero-Clear conditions, suggesting comparable levels of neurite extension despite reduced proliferation in VeroClear conditions.

Restoration of SH-SY5Y cellular viability was evident in cells cultured in VeroClear chemical 
leachate. However, levels of metabolic activity and nuclei number remained suppressed in Clear-FL conditions. Despite evident reductions in proliferation, significantly enhanced neurite lengths were observed in Clear-FL leachate conditions. This response was replicated in part when cells were cultured in VeroClear chemical leachate, which also demonstrated significantly potentiated neurite extension in culture. MAPT gene expression remained consistent with control levels in Clear-FL, suggesting contrasting cultures of abundant neuronal extension at the cost of reduced neurite length, compared to sparse cellular populations of enhanced neurite growth, indicating potentiated neuronal extension of SH-SY5Y in environments of reduced cellular confluence. ${ }^{[49]}$ Further speculative support for the aforementioned notion is evident, with neurite lengths and MAPT expression increasing in conjunction with decreasing levels of metabolic activity in both PA-12 and VeroClear conditions.

Despite apparent biologically representative values in PA-12 conditions, significant reductions were evident in HepG2 cellular viability when cultured on 3D printed scaffolds, with VeroClear and ClearFL photo-polymers eliciting near complete ablation of cellular viability. Morphological HepG2 nuclear number further supports this assertion, with reductions evident in VeroClear conditions. Despite reduced nuclear number reported in PA-12 polymer scaffolds, when taken in context with biologically comparable metabolic activity, is likely a consequence of microscopic distortion with cells and particles coexisting within different frames of the $\mathrm{Z}$ axis. Cytochrome P450 enzymatic transcription was significantly up-regulated in response to $96 \mathrm{~h}$ culture on Clear-FL and VeroClear polymer scaffolds across CYP1A1, 1A2 and 2D6 isoforms, outlining physico-chemical interference within HepG2 cellular metabolism. PA-12 polymer scaffolds elicited statistically comparable cytochrome P450 expression to that seen in control conditions, suggesting reduced influence of this polymer on CYP1A1, 1A2, 2D6 and 3A4 transcription.

HepG2 cells cultured in PA-12 chemical leachate demonstrated complete recovery and displayed comparative metabolic activity and nuclear number to control conditions; however, cells cultured in Clear-FL remained significantly reduced in number despite evident biological restoration. This response was in part replicated in VeroClear conditions, demonstrating reduced proliferation during intermediate time-points. However, cell number appeared to recover after 96 h in culture. Despite 
reductions in proliferation observed in Clear-FL, cytochrome P450 expression levels were restored to basal levels in CYP1A1, 2D6 and 3A4 isoforms across polymers. Although comparable levels to control were observed in PA-12 chemical leachate, CYP1A2 remained significantly up regulated in Clear-FL and VeroClear conditions. Despite significant transcriptional upregulation evident in CYP1A2, such values remained physiologically comparable, with increases in HepG2 cytochrome P450 expression confined to $\leq 1$-fold.

The integration of 3D printing within biological systems holds significant potential when redefining the methods utilised for the creation of scaffolds and in vitro models. Specifically, those that comprise complex cellular physiological processes. To exploit such advances in AM technology, biological facets of polymer compatibility must be considered in addition to the evaluation of design requirements and 3D printing process parameters. This research demonstrates initial critical evidence for a framework of polymer/process selection, with $\mathrm{C}_{2} \mathrm{C}_{12}$, SH-SY5Y and HepG2 cells favouring LS polymer PA-12 for applications in which cellular adherence is necessitated. Biocompatible responses observed in PA-12 are likely due to the pure formulation and manufacturing of this polymer. PA-12 3D printed via LS as evidenced within this work is consolidated using a high-powered laser, requiring no additional chemical compounds to create 3D structures. This is opposed to the laser/UV lamp polymerisation of complex photo-polymers seen in SL and PolyJet. The solubility of PA-12 is also low. This results in surfaces of reduced chemical complexity and parts that do not contain small molecules to leach. Scaffolds for in vitro systems often comprise simplistic designs due to the rudimentary methods previously utilised. ${ }^{[29]}$ The design flexibility afforded by LS provides the capability to rapidly produce, and reproduce multiple design iterations of such models. Although currently limited by the broad accessibility of this technology, recent developments have seen a trend toward commercialisation, with desktop LS printers becoming commercially accessible. ${ }^{[50]}$

Enhanced polymer/process flexibility was observed when examining the chemical leachate of SL and PolyJet photo-polymers, with cell type specific responses evident. Despite reduced cellular responses to SL Clear-FL and PolyJet VeroClear resins in the direct condition, physiologically relevant morphological and transcriptional profiles were documented in leachate conditions. Such responses 
may present the opportunity to utilise these materials within devices in which cell/polymer interaction is confined to leachates within the culture medium. Pertinent to this are bespoke perfusion systems ${ }^{[7,51]}$ and microfluidic devices, ${ }^{[11]}$ that are currently being utilised for the examination and recreation of musculoskeletal and neurological cellular physiological processes in vitro. ${ }^{[22,52]}$ The homogeneity of cytochrome P450 enzymatic activity across SL, LS and PolyJet AM processes, may also afford the opportunity to produce 3D printed fluidic devices that contain multiple cell types (Table 2).

\section{Table 2}

Biocompatibility of 3D printed polymers. - Non-biocompatible; * supports proliferation; $\Psi$ supports differentiation; \# supports physiological Cytochrome P450 expression. Completely biocompatible, experiment specific compatibility, non-biocompatible.

\begin{tabular}{|c|c|c|c|c|c|c|}
\hline \multirow{2}{*}{ AM Process } & \multicolumn{3}{|c|}{ Direct Biocompatibility } & \multicolumn{3}{|c|}{ Indirect Biocompatibility } \\
\hline & $\mathrm{C}_{2} \mathrm{C}_{12}$ & SH-SY5Y & HepG2 & $\mathrm{C}_{2} \mathrm{C}_{12}$ & SH-SY5Y & HepG2 \\
\hline Stereolithography & * & - & - & $* \Psi$ & $\Psi$ & \# \\
\hline PolyJet & * & $\Psi$ & - & * & $* \Psi$ & \# \\
\hline $\begin{array}{l}\text { Selective Laser } \\
\text { Sintering }\end{array}$ & $* \Psi$ & $* \Psi$ & \# & $* \Psi$ & $* \Psi$ & $* \#$ \\
\hline
\end{tabular}

Microfluidic systems concerned with the creation of 'organ on a chip' devices ${ }^{[22,52,53]}$ often require intricate design features that necessitate photo-polymerisation processes such as SL and PolyJet. This is primarily due to consolidation variability of sintered particles within LS designs, often preventing the removal of un-sintered material from micron-sized features. ${ }^{[43]}$ As such, although LS PA-12 provides bio-inert polymers for scaffolds necessitating cellular adherence, SL and PolyJet resins may be favoured for perfusion/screening devices dependent on cell line selection and desired phenotype. Work has been undertaken where bespoke biocompatible SL resins have been synthesised, ${ }^{[54]}$ however due to a lack of commercial availability, such research is currently limited in its translation to the wider scientific community. This further outlines the significance of readily available biocompatible 
photo-polymers elucidated within this work, specifically when aspiring to 3D print musculoskeletal, neurological and or pharmacological compatible systems.

\section{Conclusions}

This investigation observed cell type specific biocompatibility across three industry standard 3D printing processes, which affords the opportunity for experiment-specific 3D printing process and polymer selection; dependent on desired biological application and necessitated design feature intricacy. To fully exploit AM technology within bioengineering systems, future work should seek to develop a broad range of compatibility data derived from commercially available and accessible 3D printing processes, across a diverse variety of mammalian cell types. Further work should also be undertaken to investigate the printing parameters and post-curing techniques of photo-polymerised resins. By manipulating these variables, it may be possible to further minimise the leaching of toxic compounds, with a view to also reducing the time required to reach biologically compatible levels. 


\section{Acknowledgements}

This research was undertaken within a mini-centre for doctoral training (CDT) funded by Loughborough University. This work was supported in part by EPSRC Grant REF: EP/L02067X/2. 


\section{References}

[1] S. H. Masood, Rapid Prototyp. J. 1996, 2, 24.

[2] F. P. W. Melchels, J. Feijen, D. W. Grijpma, Biomaterials 2010, 31, 6121.

[3] S. A. Skoog, P. L. Goering, R. J. Narayan, J. Mater. Sci. Mater. Med. 2014, 25, 845.

[4] A. Mazzoli, Med. Biol. Eng. Comput. 2013, 51, 245.

[5] J. Korpela, A. Kokkari, H. Korhonen, M. Malin, T. Narhi, J. Seppalea, J. Biomed. Mater. Res. - Part B Appl. Biomater. 2013, 101, 610.

[6] H. Y. He, J. Y. Zhang, X. Mi, Y. Hu, X. Y. Gu, Int. J. Clin. Exp. Med. 2015, 8, 11777.

[7] S. Balakrishnan, M. S. Suma, S. R. Raju, S. D. B. Bhargav, S. Arunima, S. Das, G. K. Ananthasuresh, Biores. Open Access 2015, 4, 343.

[8] A. J. Capel, A. Wright, M. J. Harding, G. W. Weaver, Y. Li, R. A. Harris, S. Edmondson, R. D. Goodridge, S. D. R. Christie, Beilstein J. Org. Chem. 2017, 13, 111.

[9] R. Sodian, M. Loebe, A. Hein, D. P. Martin, S. P. Hoerstrup, E. V Potapov, H. Hausmann, T. Lueth, R. Hetzer, ASAIO J. 2002, 48, 12.

[10] R. Guo, A. R. Merkel, J. A. Sterling, J. M. Davidson, S. A. Guelcher, Biomaterials 2015, 73, 85.

[11] G. W. Bishop, J. E. Satterwhite-Warden, K. Kadimisetty, J. F. Rusling, Nanotechnology 2016, 27, 284002.

[12] N. P. Macdonald, F. Zhu, C. J. Hall, J. Reboud, P. S. Crosier, E. E. Patton, D. Wlodkowic, J. M. Cooper, Lab Chip 2016, 16, 291.

[13] R. Liska, M. Schuster, R. Inführ, C. Turecek, C. Fritscher, B. Seidl, V. Schmidt, L. Kuna, A. Haase, F. Varga, et al., J. Coatings Technol. Res. 2007, 4, 505.

[14] R. P. Rimington, A. J. Capel, S. D. R. Christie, M. P. Lewis, Lab Chip 2017, 17, 2982.

[15] S. M. Oskui, G. Diamante, C. Liao, W. Shi, J. Gan, D. Schlenk, W. H. Grover, Environ. Sci. Technol. Lett. 2016, 3, 1.

[16] B. C. Gross, K. B. Anderson, J. E. Meisel, M. I. McNitt, D. M. Spence, Anal. Chem. 2015, 87, 6335.

[17] C. M. B. Ho, S. H. Ng, K. H. H. Li, Y.-J. Yoon, Lab Chip 2015, 15, 3627.

[18] S. Das, S. J. Hollister, C. Flanagan, A. Adewunmi, K. Bark, C. Chen, K. Ramaswamy, D. Rose, E. Widjaja, Rapid Prototyp. J. 2003, 9, 43.

[19] E. Peris, O. Okafor, E. Kulcinskaja, R. Goodridge, S. V. Luis, E. Garcia-Verdugo, E. O’Reilly, V. Sans, Green Chem. 2017, DOI 10.1039/C7GC02421E.

[20] J. a. Inzana, D. Olvera, S. M. Fuller, J. P. Kelly, O. a. Graeve, E. M. Schwarz, S. L. Kates, H. a. Awad, Biomaterials 2014, 35, 4026.

[21] D. H. Rosenzweig, E. Carelli, T. Steffen, P. Jarzem, L. Haglund, B. Yan, Int. J. Mol. Sci. 2015, 16,15118

[22] B. N. Johnson, K. Z. Lancaster, I. B. Hogue, F. Meng, Y. L. Kong, L. W. Enquist, M. C. 
McAlpine, Lab Chip 2016, 16, 1393.

[23] K. Kamei, Y. Mashimo, Y. Koyama, C. Fockenberg, M. Nakashima, M. Nakajima, J. Li, Y. Chen, Biomed. Microdevices 2015, 17, 36.

[24] S. Tsuda, H. Jaffery, D. Doran, M. Hezwani, P. J. Robbins, M. Yoshida, L. Cronin, PLoS One 2015, 10, e0141640.

[25] S. Takenaga, B. Schneider, E. Erbay, M. Biselli, T. Schnitzler, M. J. Schöning, T. Wagner, Phys. Status Solidi Appl. Mater. Sci. 2015, 212, 1347.

[26] J. Vanderburgh, J. a. Sterling, S. a. Guelcher, Ann. Biomed. Eng. 2017, 45, 164.

[27] a Díaz-Lantada, A. Mosquera, J. L. Endrino, P. Lafont, J. Phys. Conf. Ser. 2010, 252, 12003.

[28] A. P. Sharples, D. J. Player, N. R. W. Martin, V. Mudera, C. E. Stewart, M. P. Lewis, Aging Cell 2012, 11, 986.

[29] A. S. T. Smith, S. Passey, L. Greensmith, V. Mudera, M. P. Lewis, J. Cell. Biochem. 2012, 113, 1044.

[30] N. R. W. Martin, S. L. Passey, D. J. Player, A. Khodabukus, R. A. Ferguson, A. P. Sharples, V. Mudera, K. Baar, M. P. Lewis, Biomaterials 2013, 34, 5759.

[31] N. R. W. Martin, S. L. Passey, D. J. Player, V. Mudera, K. Baar, L. Greensmith, M. P. Lewis, Tissue Eng. Part A 2015, 21, 2595.

[32] A. M. Kasper, D. C. Turner, N. R. W. Martin, A. P. Sharples, J. Cell. Physiol. 2017, DOI 10.1002/jcp.25840.

[33] A. S. T. Smith, S. L. Passey, N. R. W. Martin, D. J. Player, V. Mudera, L. Greensmith, M. P. Lewis, Cells Tissues Organs 2016, 202, 143.

[34] A. P. Sharples, N. Al-Shanti, C. E. Stewart, J. Cell. Physiol. 2010, 225, 240.

[35] R. A. Ross, B. A. Spengler, J. L. Biedler, J. Natl. Cancer Inst. 1983, 71, 741.

[36] S. Wilkening, F. Stahl, A. Bader, Drug Metab. Dispos. 2003, 31, 1035.

[37] K. Nakamura, R. Mizutani, A. Sanbe, S. Enosawa, M. Kasahara, A. Nakagawa, Y. Ejiri, N. Murayama, Y. Miyamoto, T. Torii, et al., J. Biosci. Bioeng. 2011, 111, 78.

[38] W. M. A. Westerink, W. G. E. J. Schoonen, Toxicol. Vitr. 2007, 21, 1581.

[39] S. C. Strom, J. Davila, M. Grompe, Chimeric Mice with Humanized Liver: Tools for the Study of Drug Metabolism, Excretion, and Toxicity, Humana Press, Totowa, NJ, 2010.

[40] M. T. Donato, A. Lahoz, J. V Castell, M. J. Gómez-Lechón, Curr Drug Metab. 2008, 9, 1.

[41] K. J. Livak, T. D. Schmittgen, Methods 2001, 25, 402.

[42] S. Schiaffino, A. C. Rossi, V. Smerdu, L. A. Leinwand, C. Reggiani, Skelet. Muscle 2015, 1.

[43] A. J. Capel, S. Edmondson, S. D. R. Christie, R. D. Goodridge, R. J. Bibb, M. Thurstans, Lab Chip 2013, 13, 4583.

[44] Formlabs Inc., “MSDS for Clear Photoreactive Resin,” 2018.

[45] Stratasys, “MSDS for VeroClear-RGD810 resin,” 2018. 
[46] V. Ansteinsson, H. B. Kopperud, E. Morisbak, J. T. Samuelsen, J. Biomed. Mater. Res. A 2013, $101,3504$.

[47] S. Krifka, G. Spagnuolo, G. Schmalz, H. Schweikl, Biomaterials 2013, 34, 4555.

[48] E. Yoshii, J. Biomed. Mater. Res. 1997, 37, 517.

[49] P. Lopresti, W. Poluha, D. K. Poluha, E. Drinkwater, A. H. Ross3, Cell Growth Differ. 1992, 3, 627.

[50] SINTERIT, “SINTERIT Desktop LS 3D Printer,” can be found under http://sinterit.com/, n.d.

[51] F. Kurth, A. Franco-Obregón, C. A. Bärtschi, P. S. Dittrich, Analyst 2015, 140, 127.

[52] Z. Tong, O. Seira, C. Casas, D. Reginensi, A. Homs-Corbera, J. Samitier, J. A. Del Río, RSC Adv. 2014, 4, 54788.

[53] G. Agrawal, A. Aung, S. Varghese, Lab Chip 2017, DOI 10.1039/C7LC00512A.

[54] A. Urrios, C. Parra-Cabrera, N. Bhattacharjee, A. M. Gonzalez-Suarez, L. G. Rigat-Brugarolas, U. Nallapatti, J. Samitier, C. A. DeForest, F. Posas, J. L. Garcia-Cordero, et al., Lab Chip 2016, 16, 2287. 
Feasibility and Biocompatibility of 3D Printed Photo-Polymerised and Laser Sintered Polymers for Neuronal, Myogenic and Hepatic Cell Types

\section{Supplementary Material, Macromolecular Bioscience}

Rowan P. Rimington, Andrew J. Capel, Darren J. Player, Richard J. Bibb, Steven D. R. Christie, Mark P. Lewis*.

Table S1 - Details regarding experimental adherence to ISO10993 protocol.

\begin{tabular}{|c|c|}
\hline ISO 10993 Guideline & Experimental Condition \\
\hline $\begin{array}{l}\text { Sample to be preconditioned by the same } \\
\text { processing steps as the final intended product }\end{array}$ & $\begin{array}{l}\text { Experimental protocol intended to be } \\
\text { reproducible for part designs of more } \\
\text { complex geometries and therefore a suitable } \\
\text { methodology for "final products" }\end{array}$ \\
\hline $\begin{array}{l}\text { The fluid used for extraction and the extraction } \\
\text { conditions should be appropriate to the final device } \\
\text { and its end use. }\end{array}$ & $\begin{array}{l}\text { The fluid used for extraction (cell culture } \\
\text { growth media) was the ideal solvent with } \\
\text { which to undertake the extraction as the final } \\
\text { intended use of the material was cell culture } \\
\text { applications. }\end{array}$ \\
\hline $\begin{array}{l}\text { Extraction should contain both an organic and } \\
\text { aqueous solvent }\end{array}$ & $\begin{array}{l}\text { Parts were washed with both IPA (mild } \\
\text { organic solvent selected to prevent part } \\
\text { damage) as well as aqueous growth media }\end{array}$ \\
\hline $\begin{array}{l}\text { Temperature of extraction should be high enough to } \\
\text { maximise extraction without damaging the part }\end{array}$ & $\begin{array}{l}\text { Extraction carried out at } 37^{\circ} \mathrm{C} \text { to mimic } \\
\text { culture environment, whilst not causing } \\
\text { damage to photopolymers with low glass } \\
\text { transition temperatures. }\end{array}$ \\
\hline $\begin{array}{l}\text { Ideally extraction carried out under static } \\
\text { conditions }\end{array}$ & Static conditions used \\
\hline $\begin{array}{l}\text { For synthetic polymers material thickness should be } \\
\text { between } 0.5 \text { and } 1 \mathrm{~mm} \text { in thickness }\end{array}$ & Material was $1 \mathrm{~mm}$ in thickness \\
\hline $\begin{array}{l}\text { For synthetic polymers surface area to volume ratio } \\
\text { for extraction should be } 3 \mathrm{~cm}^{2} \text { per ml. }\end{array}$ & $\begin{array}{l}\text { Surface area to volume ratio for extraction } \\
\text { utilised was } 3 \mathrm{~cm}^{2} \text { per ml. }\end{array}$ \\
\hline $\begin{array}{l}\text { Appropriate reference materials utilised throughout } \\
\text { experiment to provide both a positive and negative } \\
\text { control }\end{array}$ & $\begin{array}{l}\text { Tissue culture plastic used as a negative } \\
\text { control; however it was not considered of } \\
\text { interest to include a positive control whereby }\end{array}$ \\
\hline
\end{tabular}




\begin{tabular}{|l|l|}
\hline & $\begin{array}{l}\text { cellular death would be prevalent, offering } \\
\text { limited measurable or novel data. }\end{array}$ \\
\hline
\end{tabular}
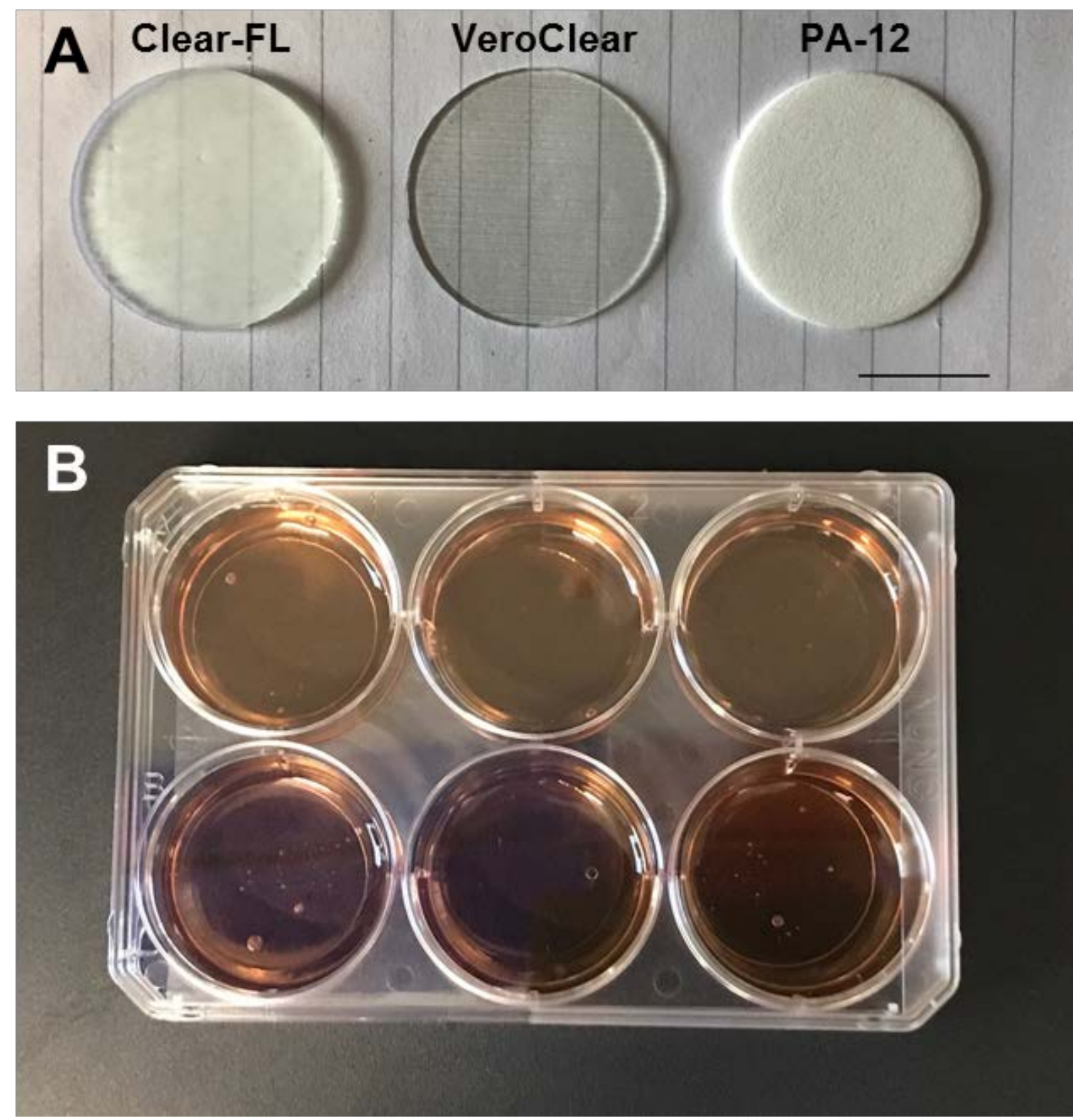

Figure. S1. (a) 3D printed samples via stereolithography (Clear-FL), polyjet (VeroClear) and selective laser sintering (PA-12). (b) VeroClear samples during 10 day incubation within $5 \mathrm{ml}$ growth medium. Scale bar $=10 \mathrm{~mm}$. 


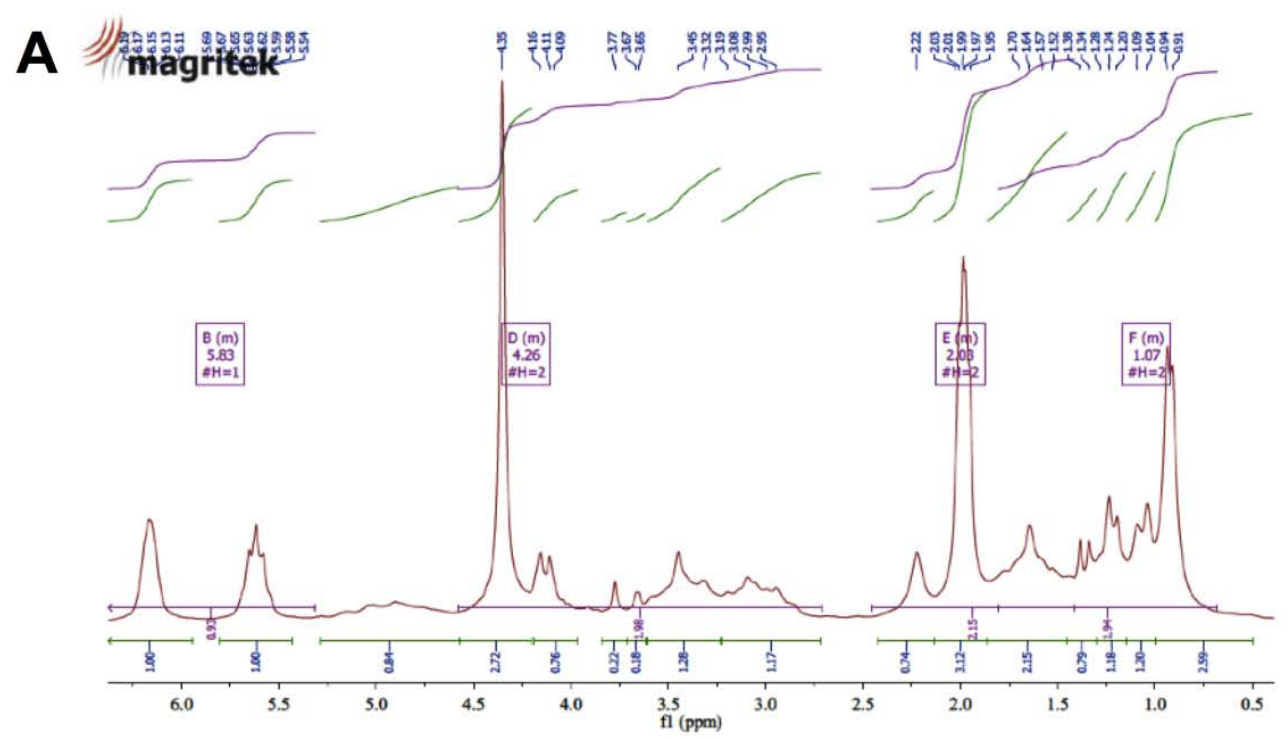

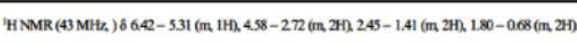

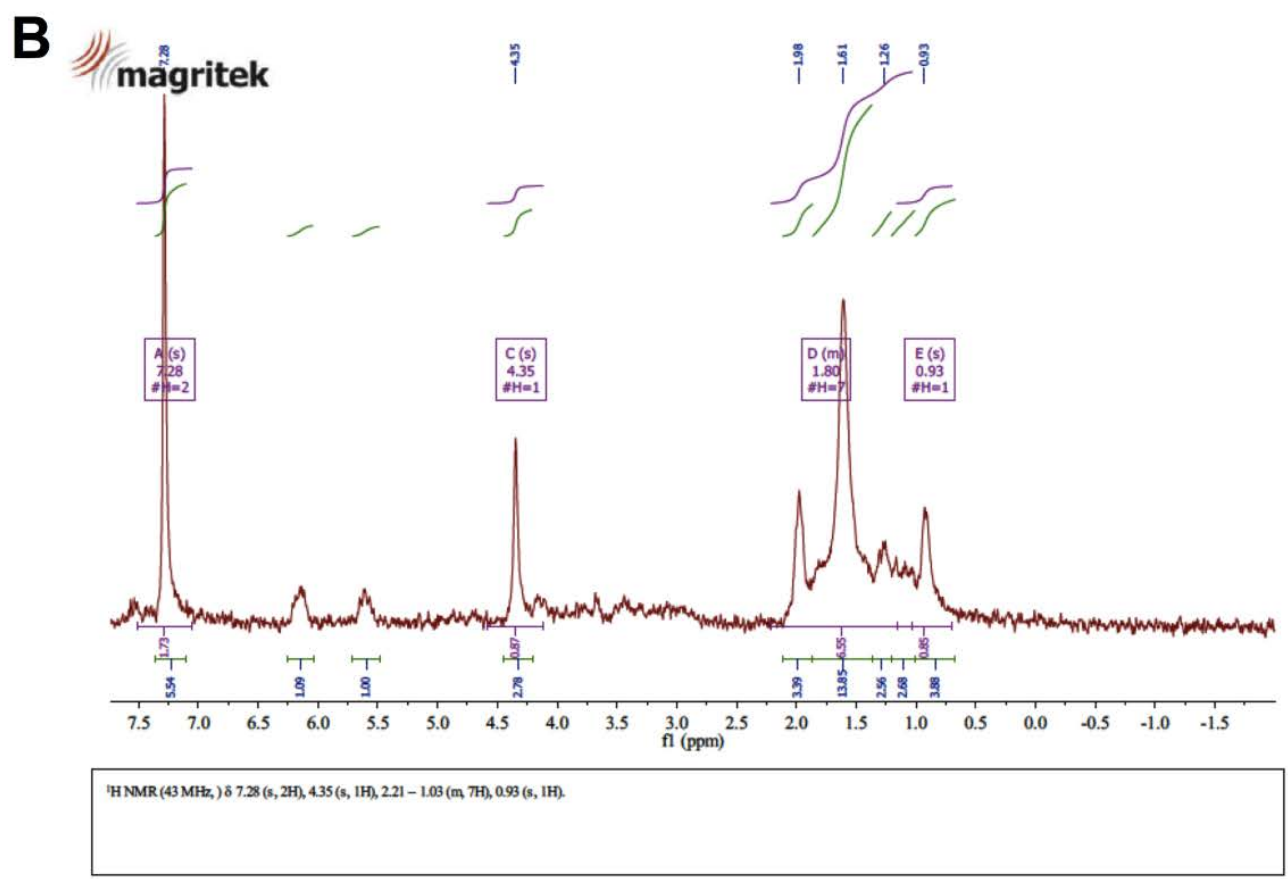

Figure. S2. Nuclear magnetic resonance (NMR) spectra for (A) Formlabs ${ }^{\mathrm{TM}}$ Clear-FLGPCL02 resin and (B) leachate from printed samples. Characteristic peaks include; ${ }^{1} \mathrm{H}$ NMR (42.5 MHz; $\left.\mathrm{CDCl}_{3}, \mathrm{ppm}\right) \delta 1-2$ (m, aliphatic, both spectra), 4.4 (s, 3H, $\mathrm{CH}_{3}$, both spectra), 5.6 (t, $1 \mathrm{H}, \mathrm{CH}$, both spectra), 6.2 (t, 1H, $\mathrm{CH}$, both spectra). 

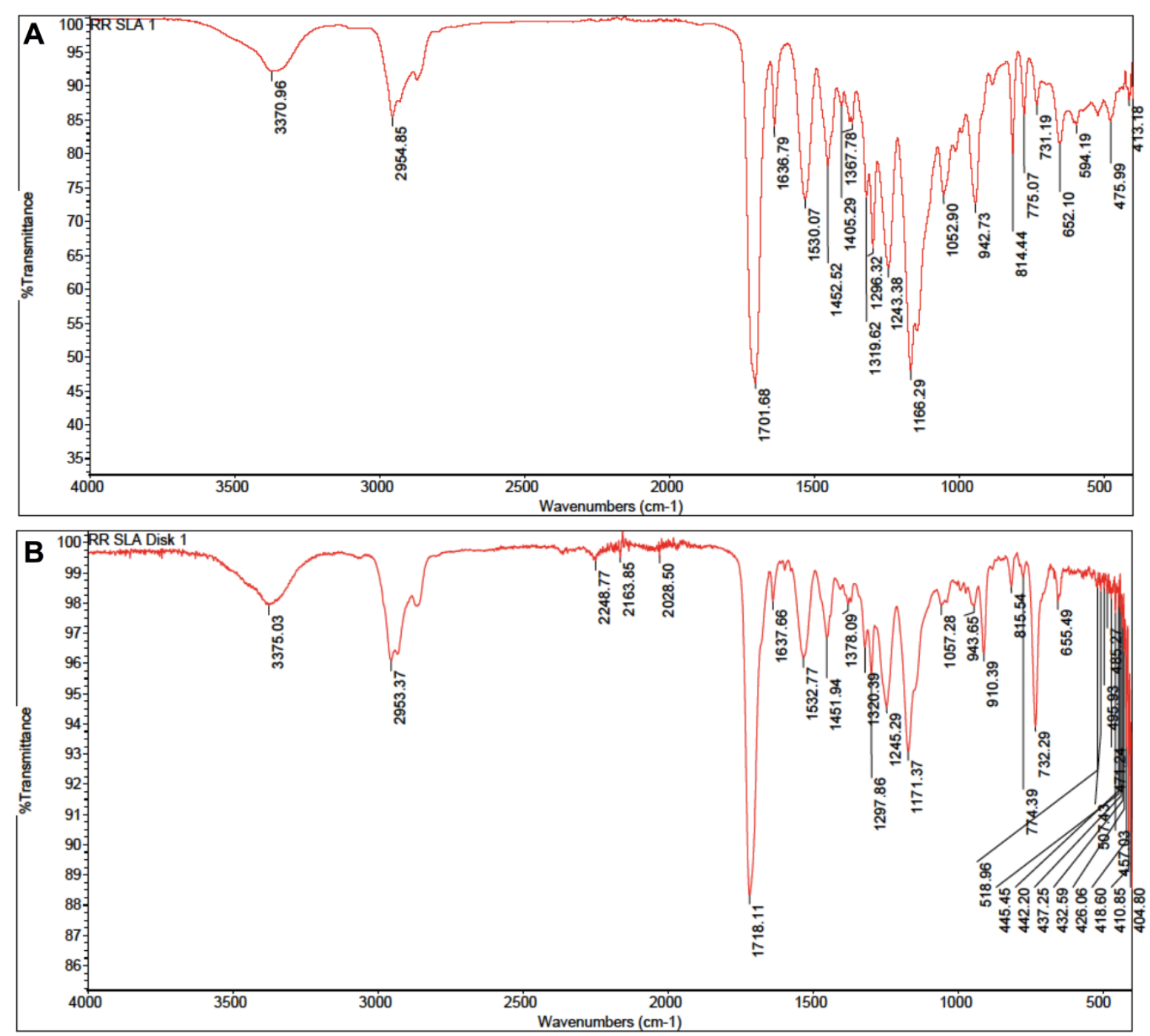

Figure. S3. Infrared (IR) spectra for (A) Formlabs ${ }^{\mathrm{TM}}$ Clear-FLGPCL02 resin and (B) leachate from printed samples. Characteristic peaks include $\left(\mathrm{cm}^{-1}\right)$; $v 3370$ (-OH, stretch, both spectra), 2955 (C-H, stretch, both spectra), 1700-1720 (C=O, stretch, both spectra), 1637 (C=C, stretch, both spectra). 
A

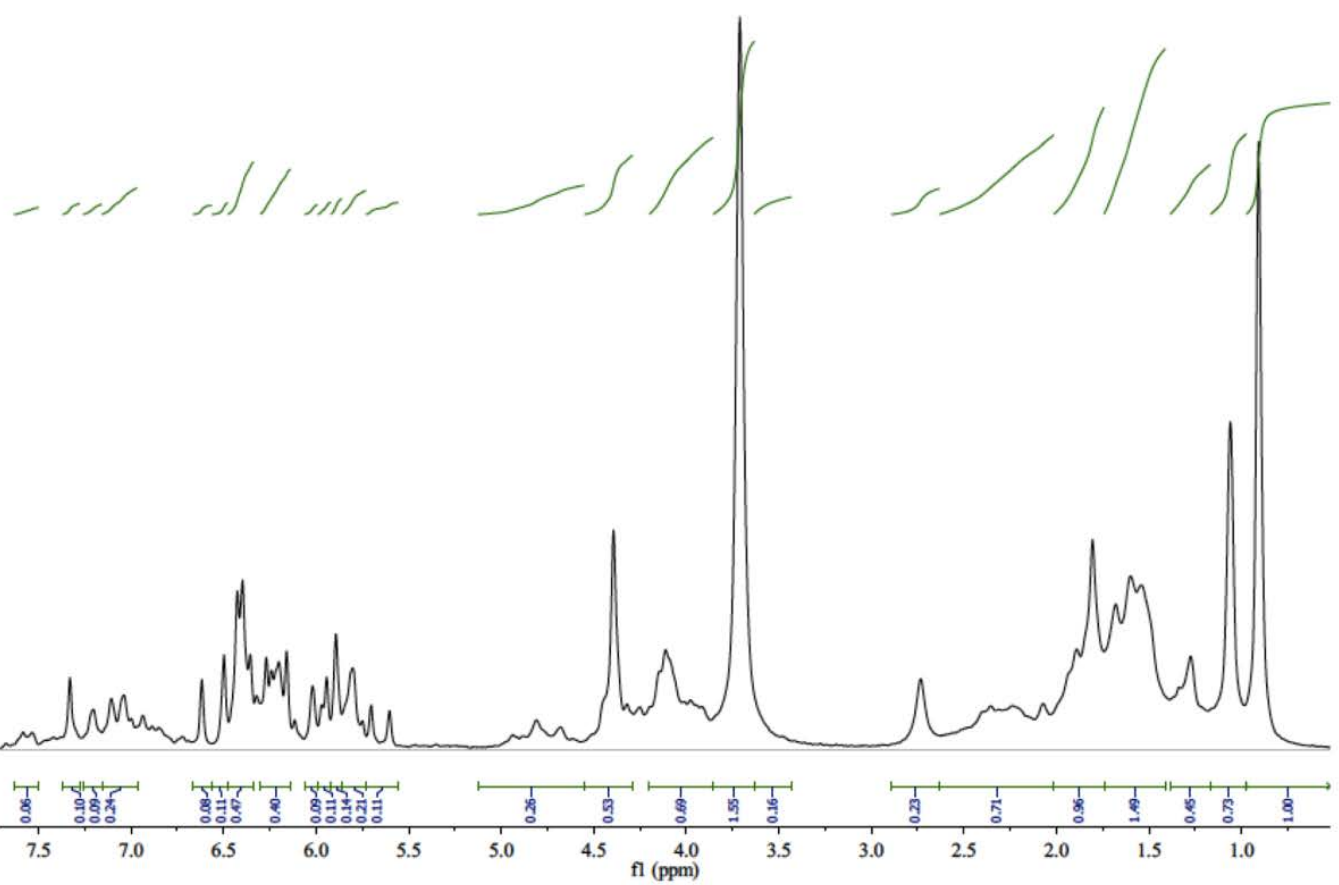

B

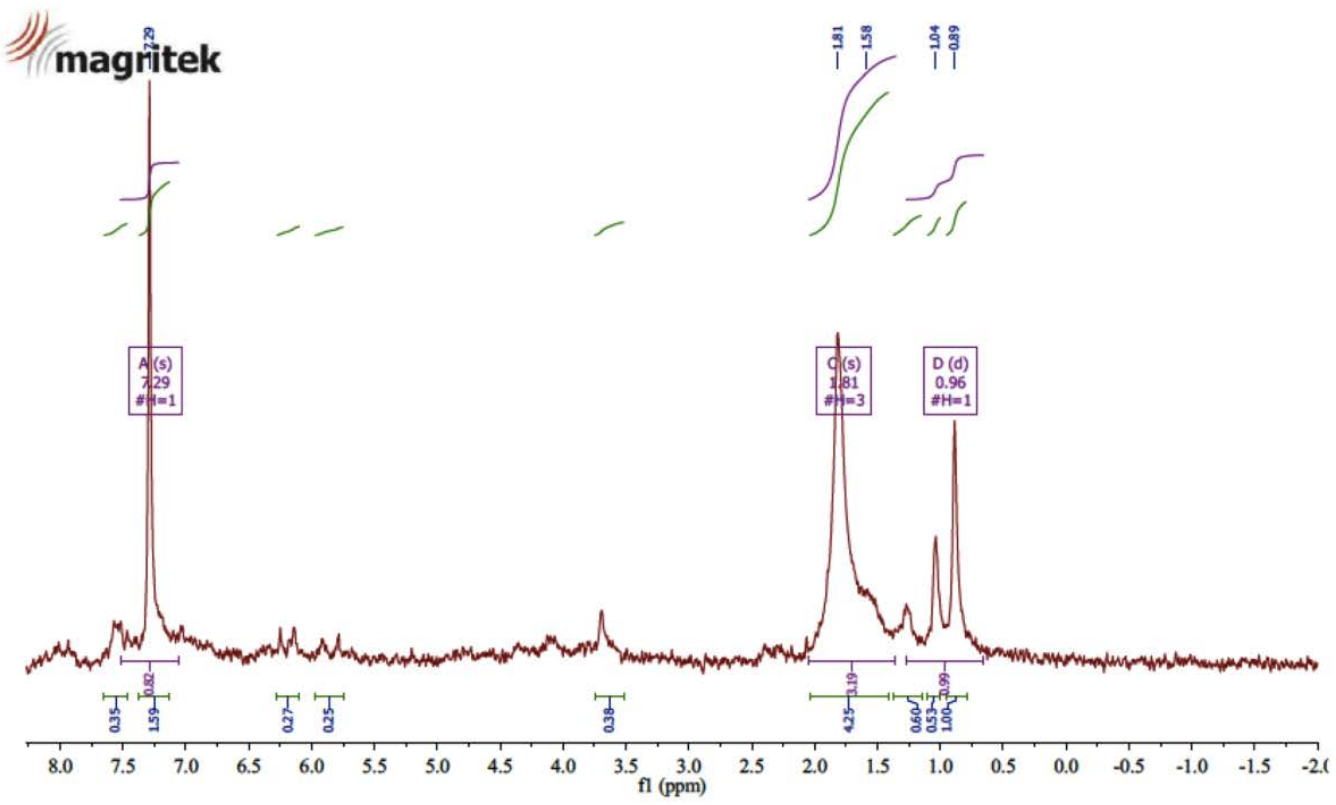

'HNMR (43 MHz, $) \delta 7.29(\mathrm{~s}, 1 \mathrm{HH}, 1.81(\mathrm{~s}, 3 \mathrm{H}), 0.96(\mathrm{~d}, J=6.6 \mathrm{~Hz}, 1 \mathrm{H})$.

Figure. S4. Nuclear magnetic resonance (NMR) spectra for (A) PolyJet VeroClear-RGD810 resin and (B) leachate from printed samples. Characteristic peaks include; ${ }^{1} \mathrm{H}$ NMR (42.5 MHz; $\left.\mathrm{CDCl}_{3}, \mathrm{ppm}\right) \delta$ 0.7-2 (m, aliphatic, both spectra), 3.7 (s, 3H, $\mathrm{CH}_{3}$, both spectra), 5.5-6.5 (m, CH, A only), 5.8 (t, 1H, CH, both spectra), 6.2 (t, 1H, CH, both spectra). 

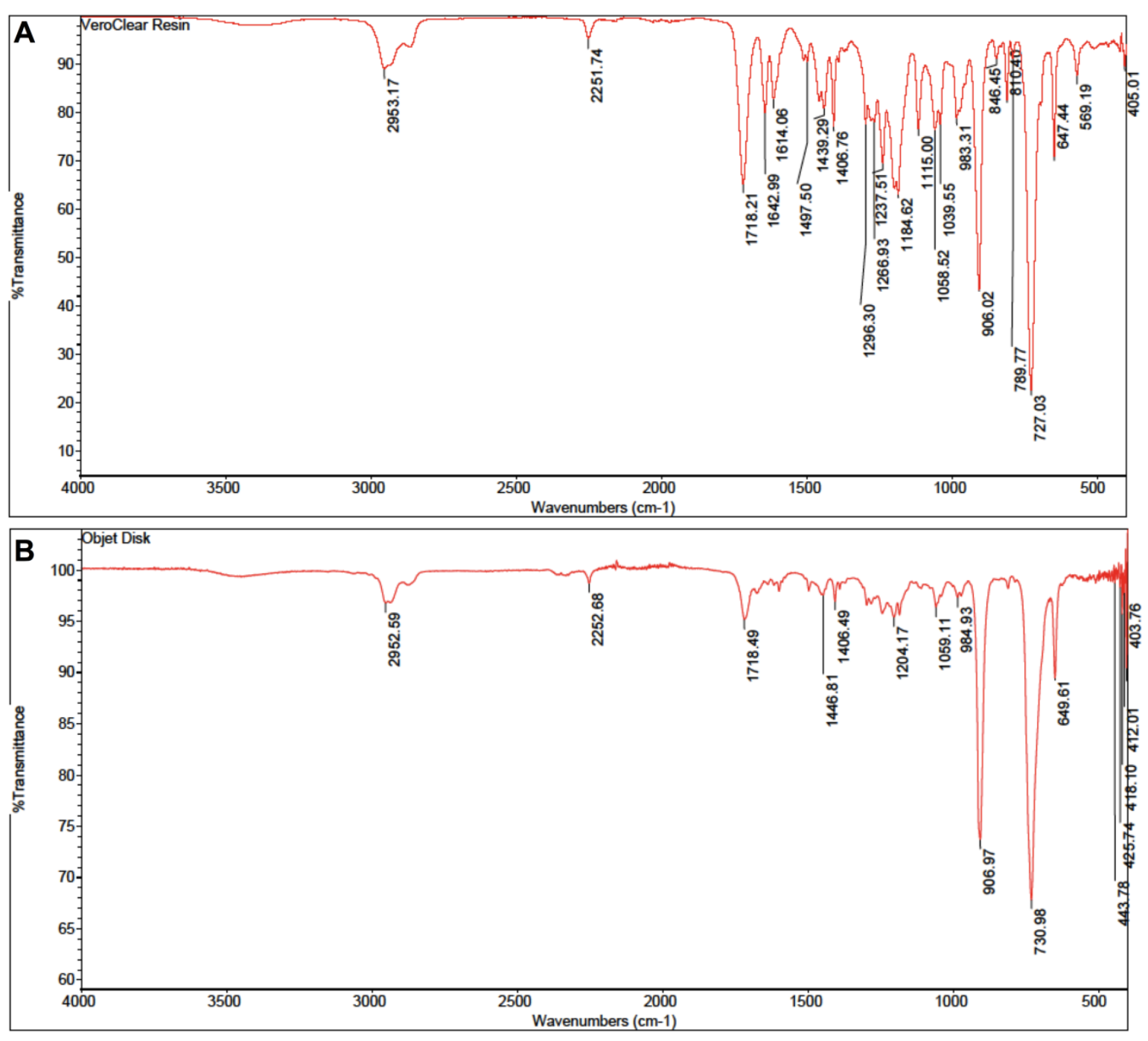

Figure. S5. Infrared (IR) spectra for (A) PolyJet VeroClear-RGD810 resin and (B) leachate from printed samples. Characteristic peaks include $\left(\mathrm{cm}^{-1}\right)$; 2955 (C-H, stretch, both spectra), 1720 (C=O, stretch, both spectra), 1640 (C=C, stretch, A only). 